\title{
ADMINISTRACIÓN CONSULTIVA AGRARIA Y ORGANIZACIÓN PROPIETARIA. EL OTRO PROCESO DE IMBRICACIÓN EN EL ESTADO DE LOS HACENDADOS ARAGONESES. 1900-1930
}

\author{
por \\ GLORIA SANZ LAFUENTE \\ Universidad de Zaragoza
}

"...tampoco bemos de abandonar ni por un momento aquellos puestos, que nos creemos con derecho y obligación de ocupar, para la guarda de los intereses corporativos que nos están confiados...»

José María Azara. 1919. Presidente de la Confederación Nacional Católico Agraria'.

RESUMEN: El artículo analiza el proceso de imbricación de la burguesía agraria organizada aragonesa en el seno de las instituciones de la administración consultiva del Estado. Se trata de recorrer en primer lugar la formación de grupos de interés agrario a escala regional y su deseo de por introducirse en instituciones administrativas, intentando convertirse en canales de representación de intereses económicos reconocidos of $i$ cialmente, en un periodo en el que se incrementaba el papel y el número de los entramados burocráticos en la gestión del Estado. Instituciones como el Consejo Superior de Fomento u otras con más poder como la Junta de Aranceles y Valoraciones, el Consejo del Banco de España o la Junta Consultiva del Crédito Agrícola se convirtieron en objeto de campañas en la sociedad agraria aragonesa por parte de estos propietarios, generando nuevas vías de penetración entre el pequeño propietario y originando tensiones entre una administración técnica en proceso de organización y unas asociaciones regionales que pretendian conservar poderes de supervisión de su actividades. En la escala local, los Consejos Provinciales de Fomento o el Provincial.

1 AZARA ViCEnTe, J. M.: (1919) Apuntes sociales agrarios de un propagandista aragonés, Zaragoza, T. Heraldo de Aragón. (Prólogo de Mariano Baselga Ramírez), pag. 178.

Hispania, LXI/2, núm. 208 (2001) 619-660 
de Economía y también las Cámaras de la Propiedad Rústica, se transformaron en centros de reunión de estos mismos propietarios organizados. Concebidos sobre todo los primeros como lugares de relación entre representantes de intereses económicos y funcionarios técnicos de la administración permitieron que los propietarios pasaran a formar parte de las redes relacionales de los hacendados agrarios acrecentando su poder a través de una prolongada y dilatada capacidad de mediación institucional.

Palabras Clave: Administración consultiva. Propietarios agrarios. Redes institucionales. Mediación. Poder.

ABSTRACT: The article addresses the making of an agricultural consultative administration in the region of Aragón at the beginning of the twentieth century. Organisations like the Asociación de Labradores de Zaragoza (A.L.Z) and the Sindicato Central de Aragón (S.C.A) developed a model of association, a commercial system (mainly in fertilisers and credit), and a leadership system. The origin of these rural organisations was closely connected with the economic crisis in the countryside in the late nineteenth century and with the search for a solution to this crisis. Around these organisations a power structure began to emerge. The state saw the organizations as representing the peasants, but they were run exclusively by landowners, for whom this was a means of fostering their begemony in rural areas. They targeted institutions like the Junta de Aranceles $y$ Valoraciones or the Consejo Superior de Fomento. In this respect, the Consejo Provincial de Fomento as a local consultative institution was a centre of relations between rural leadership, local government agronomists, and politicians.

KEY WORDS: Agricultural consultative administration. Rural organisations. Landowners. Peasants. Hegemony.

Uno de los objetivos que ya había protagonizado las asambleas agrarias de finales de siglo, era el interés reiterado de los propietarios agrarios por intervenir en la administración, en defensa de sus intereses económicos y de clase. Para ello se creaban pequeñas y dispersas plataformas, que surgían en estrecha relación los con centros locales y provinciales de poder. Desde finales del siglo XIX se había venido utilizando ya en el seno de las localidades, las vías de intervención política del consistorio, y más adelante las de la Diputación Provincial o las del Diputado a Cortes, entramados todos ellos que surgían de relaciones clientelares y mediaciones asentadas desde abajo, y que se organizaban a través de múltiples facciones políticas. A principios del siglo $\mathrm{XX}$, junto a estos últimos, y estrechamente ligados a ellos, comenzaron a emplearse mecanismos de presión, a través de organizaciones de intereses económicos sectoriales, que de manera muy fragmentaria empezaban a asentarse regionalmente. La formación de estos grupos de interés se desarrolla paralela al proceso de transformación de la administración Pública, intentado convertirse en canales de intervención oficial reconocidos por el Estado y buscando la ocupación de numerosos órganos consultivos. Estas entidades crecientemente pujantes, definidas por 
una pluralidad de intereses provinciales, acabaron atribuyéndose la «representación», en medio de un proceso de redefinición de los roles sociales agrarios, en su relación con el Estado y con los otros grupos económicos.

Con el desarrollo de los entramados organizativos agrarios y con su asentamiento desde comienzos de siglo, su actividad en defensa de intereses concretos comenzó a operar a través de «relaciones con diputados» o « viajes a la Corte», unas vías, que seguirán siendo sin duda los más poderosos mecanismos de intervención política. Comenzaba a aparecer además un claro interés por ocupar entramados administrativos, en los que se reconocía oficialmente su capacidad de representación respecto a la totalidad de la sociedad agraria. Estas dimanaciones del poder central, no sólo desarrollaban sus actividades bajo la tutela y supervisión de los grupos de poder económico, sino que se convertían en lugar de encuentro de élites organizadas a las que los entramados legislativos del Estado les fueron reconociendo un estatus oficial, como representantes de intereses agrarios, comerciales o industriales ${ }^{2}$.

Era J. PAN MONTOJO 3 , quien subrayaba hace pocos años la necesidad de llevar a cabo un estudio de la administración española, tanto de la activa como de la consultiva, de sus relaciones con los grupos de poder, de los límites de sus actividades, o del proceso de privatización de la representación de intereses, y de la labor de las organizaciones agrarias en este sentido. A lo largo del siglo XIX, una de las vertientes de la construcción del Estado liberal había estado asentada tanto sobre la formación de organismos centrales relacionados con el Ministerio de Fomento, como de centros periféricos de la administración, que intentaban responder a unas necesidades básicas de articulación del Estado liberal con los poderes provinciales y locales ${ }^{4}$. Se trataba, como ha señalado C.

2 Existe una pluralidad de instituciones respecto a las que existió un interés propietario por participar, y que estaban relacionadas con las relaciones laborales, el comercio o la producción. Una intervención, que creó luchas importantes entre estos entramados. Referencias por ejemplo en relación con el Instituto de Reformas Sociales, el Instituto Nacional de Previsión, la Junta de Aranceles y Valoraciones, la Junta Central de Abastos, la Delegación Regia de Pósitos o la Junta Nacional del Comercio Español en Ultramar en DEL REY REGUILLO, F.: (1992) Propietarios y patronos. La política de las organizaciones económicas en la España de la Restauración, 1914-1923, Madrid, Ministerio de Trabajo y Seguridad Social. pag . 65/75.

3 PAN Montojo, J.: (1995) «La administración agraria en España, 1847-1907» en Noticiario de Historia Agraria, $\mathrm{n}^{\circ} 10$, pag. 67-88.

4 GARCÍA DE EnTERRÍA, E.: (1985) La administración española, Madrid, Alianza, pag. 18-20. También pueden servir como referencias, aunque más centrado en "los organigramas de la administración» que en la «historia que llevó a estos». GARCíA MADARIA, J.M.: (1982) Estructura de la administración central: 1808-1931. Madrid, Instituto Nacional de la Administración Pública. esp. 177-277. GuaITA, A.: (1984) El Ministerio de Fomento: 1832-1931, Madrid, Instituto de Estudios de la Administración Local. Recientemente aparece este interés en, AGUIRREAZKUENAGA, J.: (1996) «La construcción burocrática del Estado Liberal Español (1833-1854). Un banco de datos para el estudio del personal administrativo y la génesis de la sociedad civil» en Historia Contemporánea, $\mathrm{n}^{\circ}$ 13-14, pag. 111-134. 
FUMIAN, de «lugares» de mediación entre la competencia del poder y los intereses, ${ }^{5}$ que introducen el análisis administrativo en el interior de una estructura social, productiva y de mediación política. Dentro de este complejo sistema, existía una organización consultiva, que será la que nos ocupe, de carácter general para Fomento y de composición mixta, que estaba formada por elementos oficiales y representativos, y en la que tendrán mucho que decir las organizaciones de propietarios ${ }^{6}$. Durante este periodo, el Consejo Superior de Fomento y los provinciales, con continuas modificaciones y alteraciones en sus composición y funciones, irán configurando un entramado consultivo con escasa persistencia en su diseño administrativo y funciones progresivamente reducidas hasta los años treinta, que descansará en manos de los dirigentes agrarios organizados en Aragón.

No es el objetivo de este artículo, llevar a cabo un análisis en profundidad de todos estos problemas para el caso aragonés, ya que necesitaría de un estudio específico, sin embargo, si que se pretende analizar el interés mostrado por los promotores de entidades agrarias por intervenir y ocupar cargos administrativos de carácter consultivo, los enfrentamientos de un lado entre "técnicos» y «propietarios organizados» o las conexiones establecidas en el ámbito regional entre los ingenieros agrónomos de los Servicios y las organizaciones agrarias de los hacendados. Aunque a lo largo del siglo XIX, ya se había producido un proceso general de declive de una administración consultiva de carácter sectorial, en manos de una penetración cada vez mayor de los técnicos agronómi$\cos ^{7}$, durante siglo XX, la consolidación de los fragmentarios y divididos grupos de presión agraria, permitió reclamar a éstos, como señalaba José María Azara, «aquellos puestos que nos creemos con derecho y obligación de ocupar», en medio eso si, del progresivo asentamiento de una administración profesional y técnica ${ }^{8}$. Comenzaba así un proceso de intervención de los entramados organizados de los propietarios, sobre todo tras la renovación administrativa de 1907, cuando las organizaciones agrarias poseían ya grandes entidades asentadas en varias provincias. Con este motivo, se generaba un choque entre unas

s Ver «Il governo dell'agricoltura in Italia e in Francia 1914-1940» en Fumian, C.: (1996) Possidenti, Roma, Meridiana, esp. pag. 153.

6 JORDANA DE POZAS, L.: (1961) «Ensayo sobre la administración consultiva y de Fomento en España.» en Estudios de la administración local y general, Madrid, Instituto de Estudios Políticos. pag. 433. ( Publicado como anexo a Consejo Provincial De Fomento de Zaragoza ( 1917) Memoria general de los trabajos realizados durante el año 1916, Zaragoza, Tipografía del Hospicio Provincial.

7 BOUSSARD, Isabel: (1983) «Fontionnaires et notables agricoles en France» en Italia Contemporanea, $\mathrm{n}^{\circ} 153$, pag. 51-68. PAN MONTOJO, J.: (1997) «La naissance des associations agraires en Espagne 1833-1898», HES, Avril- Juin, pag. 167-188. «Enfin, il existait une administration consultive dotée d'un soupçon de représentation sectorielle, en phase de déclin accéléré en raison de la consolidation de l'agronomie administrative». pag. 188.

8 FERNÁNDEZ PRIETO, L. (1998) «La política agraria del Estado Español contemporáneo hasta 1936. Del propietario innovador al fomento de la innovación en la pequeña explotación», Historia Contemporánea, 17, pag. 264. 
asociaciones, que intentaban acrecentar su presencia en los nuevos centros consultivos y por otro, los esfuerzos titubeantes de la administración por llevar a cabo esa organización técnica con mayores atribuciones.

Esta participación significaba una nueva componente de poder para esta burguesía organizada, que además hacía en un principio de sus instituciones patronales y de si mismos como «clase generale», los únicos que por derecho podían representar unos intereses agrarios sin embargo heterogéneos, y que afectaban a clases sociales plurales. En su actuación a escala nacional no todas las entidades regionales iban a tener la posibilidad de intervenir en la misma medida, sino que esta capacidad estuvo relacionada con el propio poder económico y con las relaciones políticas de la entidad en cuestión. Esto llevó a que tanto la Asociación de Labradores de Zaragoza (ALZ) como el Sindicato Central de Aragón (SCA) se erigieran en representantes de Aragón, frente a entidades menos pujantes y de fundación más tardía como la Asociación de Labradores y $\mathrm{Ga}$ naderos del Alto Aragón (ALGAA) o la Federación Turolense de Sindicatos Agrícolas Católicos (FTSAC). En el caso de la ALZ, que será en la primera década la asociación, que participará en numerosas instituciones relacionadas con la representación de intereses agrarios, a la fuerza del patrimonio de sus dirigentes, a sus relaciones con la representación política o con los órganos de gestión del agua, se iba a unir una importante labor, tanto en centros como los renovados Consejos Provinciales de Fomento o como en el Consejo Superior de Fomento, entre otras instituciones nacionales. De este modo, un reducido grupo de la burguesía agraria provincial ocupaba representaciones y mediaciones colectivas, que eran convenientemente utilizadas en sus relaciones con otros sectores agrarios y en definitiva garantes de la consolidación de su propio poder como grupo.

Este temprano interés mostrado por «los representantes de los agricultores», para incrementar su presencia como "vocales» en instituciones en las que se dirimían cuestiones agrarias, se producía en un contexto, el de finales del siglo XIX y principios del XX, en el que se incrementaba el papel y el número de los entramados burocráticos en la gestión del Estado, se construían organismos definidos determinados por leyes con funciones divididas y jerarquías de poder y se perfilaban sistemas de reclutamiento entre sectores con una formación técnica especializada, que provocaron incluso enfrentamientos entre «técnicos» y "grupos de interés», a la hora de definir competencias sobre la gestión. Esta definición de competencias entre la administración consultiva y activa, que ya había protagonizado conflictos a lo largo del siglo XIX ${ }^{9}$, será también por ejemplo, el motivo de un choque entre la Asociación de Ingenieros Agrónomos y miembros de centros consultivos de la administración provincial, formados por representaciones de la burguesía agraria organizada. La Asociación de Agricultores de España se convertía en la interlocutora de la segunda, intentando en todo momento incrementar su labor de supervisión de proyectos o informes, y

9 PAN MONTOJO, J.: (1995) Op. cit. pag. 68.

Hispania, LXI/2, núm. 208 (2001) 619-660 
procurando asentar esa intervención en una base legal. No se trataba en realidad de un aspecto privativo de la configuración de los órganos de administración agraria en España, ya que en Italia, Alemania o Bélgica también el diseño de una «representación oficial de la agricultura» se convirtió en una fuente de problemas, marcado además por lo que desde las nacientes organizaciones agrarias se consideraba «escasa presencia» ${ }^{10}$.

Además de la administración relacionada con el Fomento, los propietarios organizados aragoneses también mostraron un interés creciente por hacer valer el peso de su organización, convirtiéndose en «defensores de los sagrados intereses cerca de los poderes públicos» en otras instituciones, que se arrastraban del siglo XIX, como era el caso de la Junta de Aranceles y Valoraciones, o buscarán a finales de los años veinte, ocupar la representación de la agricultura en el Consejo del Banco de España o en la Junta Consultiva del Crédito Agrícola, cuando sus entramados crediticios se habían asentado, e incluso se formaban las primeras entidades que los agrupaban como la Confederación de Cajas de Ahorros ${ }^{11}$. Cualquier centro el que se atendieran actividades relacionadas con la política agraria general o cuya gestión afectara a los entramados crediticios y de ahorro de los propietarios organizados, se convirtieron en el objetivo de campañas de propaganda y llevaron a sistemas electorales y candidaturas entre los sindicatos agrícolas locales, con el fin de situar a los candidatos de las dos principales organizaciones agrarias aragonesas, Asociación de Labradores de Zaragoza (ALZ) y del Sindicato Central de Aragón (SCA) más adelante, como representantes en organismos oficiales.

Así pues, con la provisionalidad que confiere la existencia de una escasa investigación en este sentido, y con el único objetivo de constatar la presencia y el interés de los propietarios organizados aragoneses por incrementar o mantener su capacidad de intervención en los centros de la administración, comenzaremos por distinguir dos niveles espaciales diferenciados. Por un lado, la actividad llevada a cabo en relación con entramados agrarios organizados de otras provincias a principios de siglo a escala nacional, con el fin de obtener un reconocimiento oficial de sus organizaciones frente a las Cámaras Agrícolas y de in-

${ }^{10}$ Sobre los debates ocasionados por esta búsqueda de la «representación oficial de la agricultura» en el caso del Bélgica, VAN MOLLE, L.: (1989) «Le centenaire du Ministere de l'agriculture. La politique agricole belge dans son contexte economique, social, politique et adminitratif au cours de la periode 1884-1984» en Agricontact (Numèro spécial), septembre, $\mathrm{n}^{\circ}$ 154. esp. pag. 50-51. WILS, Lode: «L'organisation politique et la représentation des intérêts des agriculteurs en Belgique» en VILlANI. P.: (1986), pag. 154-158. Aunque centrado en un estudio legal, interesantes propuestas de análisis sobre las fricciones entre el despliegue burocrático-administrativo y el desarrollo de grupos de interés en Italia en GozzI, G.: "Organizzazione degli interessi e razionalità amministrativa in Italia tra Otto e Novecento» en Idelogie corporative e modelli corporatisti (a cura di S. PIRETTI), Materiali del Dipartimento di Politica, Istituzione, Storia. Università di Bologna, 1985. También, CALANDRA, P.: (1972) L'amministrazione dell'agricultura, Bologna.

11 FORNIES CASALS, J.F. (1978) «El nacimiento de la Confederación Española de Cajas de Ahorro Benéficas y su vinculación con la política financiera nacional» en Cuadernos económicos del I.C.E. $\mathrm{n}^{\circ}$ 7-8.

Hispania, LXI/2, núm. 208 (2001) 619-660 
tervenir en la administración consultiva del Estado con sede en la capital central. Posteriormente, pasaremos a analizar la imbricación de los dirigentes agrarios en el Consejo Provincial de Fomento de Zaragoza, señalando algunas de las labores realizadas por esta institución.

1. Del CONSEJo SUPERIOR DE FOMENTO Y LA JUNTA DE ARANCELES Y VALORACIONES AL CONSEJO DEL BANCO DE ESPAÑA: LA BURGUESÍA ORGANIZADA ARAGONESA EN LAS INSTITUCIONES CENTRALES.

La búsqueda de un reconocimiento oficial de las «verdaderas organizaciones agrarias», frente a las anquilosadas cámaras agrícolas, entre cuyos dirigentes el Estado solía delegar la capacidad representativa, fue convenientemente reiterada a lo largo del siglo por los entramados organizativos propietarios. Todavía en 1899 por ejemplo, la ausencia de organizaciones propietarias en Aragón, llevaba a que las Cámaras Agrícolas tomaran parte casi en exclusiva, en la elección de vocales-representantes agrícolas en la Junta del Comercio de Exportación..$^{12}$ A principios de siglo sin embargo, la aparición de entidades agrarias organizadas poderosas, como era el caso de la Asociación de Labradores de Zaragoza en Zaragoza, comenzó a dar lugar a las primeras acciones organizadas, con el objetivo de incrementar la presencia de estas entidades en el seno de los entramados consultivos centrales. Unos intentos, que no iban a reducir sin embargo la labor de los centros oficiales, considerados como representantes privilegiados, y cuyo persistente reconocimiento llevará a ocupar todos sus cargos a los dirigentes de la ALZ y del SCA, e incluso a que la primera, en 1917, cuando ya se había producido el proceso de cooptación de la entidad oficial zaragozana en manos privadas, considerase que la representación de la agricultura debía estar en manos de una cámara agrícola en cada provincia, que estaría gestionada por los mismos propietarios dirigentes de las organizaciones privadas. ${ }^{13}$ Se pasó así a lo largo del siglo, de la lucha abierta frente a las cámaras, a la simple ocupación por parte de los entramados propietarios, buscando dirigir así su carácter consultivo reconocido por el Estado.

Tras las reformas del bienio 1906-1907, que ahondaban en el modelo burocrático e incrementaban la actividad de los sectores técnicos, también se producía una reorganización de la administración consultiva central después de un periodo de titubeos, que coincidía además con el asentamiento definitivo de organizaciones de intereses industriales y agrarios. La reforma de Augusto González Besada entre 1907 y 1908, suponía por un lado, el reconocimiento de la representación de intereses profesionales y por otro, la creencia de que

\footnotetext{
12 RD. 2-2-1899. Junta del Comercio de Exportación.

13 EM, 23-4-1917. "La representación de la agricultura española. Contestación de la Asociación de Labradores al formulario emitido por la Dirección General de Agricultura Minas y Montes».
} 
estos no debían limitarse a la acción consultiva, sino a la intervención activa y directa ${ }^{14}$. Unas premisas, que dieron lugar a la oposición de sectores técnicos y a una pronta modificación de estas disposiciones, pese a la satisfacción con que se recogieron por parte de la Asociación de Agricultores de España.

Ya cuando se organizaba en 1907 el Consejo Superior de la Producción y del Comercio (RD 17-5-1907), se convocaba una asamblea general por el gobierno en mayo, a la que acudían representantes de las Cámaras de Comercio y asociaciones industriales y agrarias, para que estas instituciones, junto con la Junta de Comercio Internacional ${ }^{15}$, se convirtiesen en principales órganos consultivos, o como el propio decreto señalaba en «un lazo entre gobernantes y gobernados». A este Consejo, y a sus profundas atribuciones, contestadas ya en 1908 por la Asociación de Ingenieros agrónomos, al considerar supeditadas sus funciones como grupo profesional a sectores ajenos a una preparación técnica ${ }^{16}$, le sucedía rápidamente el Consejo Superior de Fomento (RD.9-11-1910), y su extensión provincial, los Consejos Provinciales de Fomento, que reducían considerablemente las atribuciones concedidas al antiguo Consejo ${ }^{17}$.

Este Consejo Superior se constituía como cuerpo consultivo del Gobierno, en lo referente a todos los asuntos propios del Ministerio de Fomento y poseía además capacidad para hacer propuestas, en relación con aquellas intervenciones que se consideraran importantes para los diversos intereses económicos. Además de su labor como órganos colegiados, a cuya capacidad de asesoramiento y deliberación se sometían los diversos proyectos e iniciativas, se subrayaba su intervención en el reparto o adjudicación de toda clase de premios o subvenciones concedidas por las Leyes del Presupuesto. Una actividad esta última, que le otorgaba un importante poder en su relación con las asociaciones agrarias locales, que solicitaban esas escasas subvenciones. En su composición, se mezclaban los sectores técnicos y los representantes de intereses económicos. Así, estaba compuesto por vocales natos -Directores generales, Presidentes de los Consejos de Obras Públicas, de Minas y de las Juntas Consultivas Agronómicas y Forestal entre otros, y de otros 30 electivos. Entre estos últimos, y a diferencia del siglo XIX, la representación recaía en las organizaciones de intereses económicos, que en el caso de la agricultura, todavía procedía de los entramados oficiales de las Cámaras Agrícolas y de la Asociación General de Ganaderos del Reino.

\footnotetext{
14 JORDANA DE POZAS, L. (1961) Op. cit. pag. 445.

15 Las actividades de esta institución quedaban en manos del propio Consejo de la Producción y del Comercio en 1909. RD. 29-1-1909.

16 Sobre la temprana oposición de estos sectores técnicos al Consejo, AHPH. Sección Joaquin Costa. Copia mecanografiada de la propuesta elevada al Gobierno por Vicente Alonso Marti. Presidente de la Asociación de Ingenieros Agrónomos. 16-2-1914. C.4. pag.1.

17 CONSEJO SUPERIOR DE FOMENTO. (1920) Reseña bistórica de estos consejos. Disposiciones legales por que se rigen y funciones que deben desempeñar en los servicios de plagas del campo, crédito agrícola y otros, Madrid, Sobrinos de la sucesora de M. Minuesa de los Ríos.
} 
Fue precisamente esta reducción de los elementos de representación a las instituciones oficiales, lo que motivó una primera campaña de oposición del primer entramado que reunía a los dirigentes de las grandes federaciones agrarias existentes ya por aquella época: la Unión Agraria Española. Una institución formada por dirigentes de las principales federaciones agrarias existentes y cuyo objetivo único era intervenir en aquellos aspectos que afectaban de forma conjunta a los entramados organizativos propietarios. Entre sus demandas iba a ocupar un papel relevante el interés común por exigir «su puesto en la administración». En realidad, todas estas demandas venían formando parte y se irán reiterando en las dinámicas de congresos de agricultura ( Valladolid, 1902, Valencia 1904, Zaragoza, 1910...) de la primera década de siglo. La Unión Agraria, pese a mantenerse el carácter autónomo de las iniciativas organizativas agrarias en cada provincia o región, promovía una labor conjunta para defender entre otros su reconocimiento en el seno del Estado. Desde la Junta Directiva, de la Unión Agraria, el Conde de Torres Cabrera realizaba ya en 1907 un Informe sobre la integración de la clase agraria en el Estado, que tenía como fin defender la unidad de las grandes organizaciones para, como se señalaba significativamente, «ocupar en la vida pública el lugar que por derecho natural nos corresponde» ${ }^{18}$. En 1910 escribía este mismo dirigente a Tomas Costa, miembro de la Federación Agraria de Castilla la Nueva, subrayando la necesidad de incrementar la participación de las organizaciones propietarias en estas instituciones, porque «las genuinas representaciones de las clases sociales» debían incrementar su presencia en la labor del Estado ${ }^{19}$. Por las mismas fechas se producían también protestas de organizaciones agrarias catalanas, que consideraban, que los consejos provinciales y el superior, se formaban con una gran cantidad de vocales natos, excluyendo además la voz y el voto de las organizaciones agrarias ajenas a los entramados oficiales de las cámaras agrícolas ${ }^{20}$. Los propietarios organizados pretendían así hacer valer el peso de sus entidades, para obtener una presencia directa en el seno de la administración y en contacto con los órganos de decisión.

En el caso aragonés existía un progresivo proceso de cooptación de la institución oficial en manos de dirigentes de la poderosa ALZ, que serían los encargados de dirigir las protestas. Esta entidad zaragozana no sólo presentaba como candidato al vocal de la organización y futuro presidente de la ALZ Francisco Bernad Partagas, sino que éste era uno de los elegidos en representación de la agricultura, formando parte incluso del Consejo Permanente del Consejo Superior. En realidad, y a pesar de las quejas de los hacendados organizados, la cooptación de los órganos oficiales quedaba también puesta de manifiesto en el caso del resto de los representantes de la agricultura. Junto al propietario y

\footnotetext{
18 BALZ, octubre 1907. Integración de la clase agraria en el Estado.

19 AHPH. Sección Joaquin Costa. Carta del Conde de Torres Cabrera a Tomás Costa. 1910. C.15.

${ }^{20}$ ER, 28-12-1910. Art. Jaime Raventos. Sobre la formación de los Consejos de Fomento.
} 
abogado de la ALZ se encontraban Mariano Cluá Angles, Antonio Falcón y Velasco, presidente de la Cámara Agrícola de Hellin y miembro de la Federación Agrícola de Levante y Tomas Costa Martínez, hermano de Joaquin Costa y representante de la Federación Agrícola de Castilla La Nueva ${ }^{21}$. En realidad, estos propietarios organizados no inauguraban esta presencia, que ya se había producía en Consejo de la Producción, en el que intervenían Manuel Iranzo Benedito, el marques de la Frontera o Ignacio Girona y el Conde de Torres Cabrera, pero si mostraban un interés creciente por obtener el reconocimiento público de sus organizaciones privadas como vías únicas de elección y hacían de la ocupación de estos centros uno de los argumentos reiterados en sus campañas de propaganda en la sociedad agraria.

1. Representantes de la agricultura en el Consejo Superior de Fomento . 1911

\begin{tabular}{c|c|c}
\hline Representante & Cargo & Entidad \\
\hline Francisco Bernad Partagas & Vocal & Asociación de Labradores de Zaragoza \\
\hline Antonio Falcón y Velasco & Vocal & Federación Agraria de Levante \\
\hline Tomas Costa Martínez & Vocal & Federación Agraria Castilla la Nueva \\
\hline Mariano Cluá? Angles & Vocal & sd \\
\hline
\end{tabular}

Fuentes: MINISTERIO DE FOMENTO (1911) Consejo Superior de Fomento, Madrid, Imp. y encuadernación de V. Tordesillas, 1911. pag. 5.

Entre los objetivos de estos propietarios movilizados en defensa de sus intereses se encontraba la idea de trasladar la labor de otros centros burocráticos a la actividad de este consejo. En este sentido, se redactaba un proyecto destinado a la modificación del Reglamento del Consejo Superior de Fomento, en el que trataba de introducir algunos cambios destinados a reducir la presencia de funcionarios y técnicos, en favor de los representantes de intereses agrarios. Así por ejemplo, respecto al artículo $7^{\circ}$, que proponía el nombramiento como vocales natos del Consejo Superior a los presidentes de los Consejos de Obras Públicas, Minas, a las Juntas Consultivas Agronómicas, Forestales y de la Industria Trabajo y Comercio, Tomás Costa subrayaba «la necesaria disolución de estos consejos». Una propuesta, que acabaría siendo finalmente rechazada en el proyecto de modificaciones presentadas ${ }^{22}$. Por otro lado, también se intentaba

${ }^{21}$ Ministerio de Fomento (1911) Consejo Superior de Fomento, Madrid, Imp. y encuadernación de V. Tordesillas, 1911. pag. 5. Sobre los apoyos obtenidos por Tomas Costa, AHPH. Sección Joaquin Costa. Lista de cámaras agrícolas que ofrecen votarme para el Consejo. (sin fecha/pos. 1910). C.86. También habían concurrido a las elecciones otros propietarios representantes de entidades agrarias importantes como Guillermo Boladeres, Eusebio de Puig o José Elias de Molins.

${ }^{22}$ AHPH Sección Joaquin Costa. Modificación del Proyecto de Reglamento del Consejo Superior de Fomento. 24-2-1911.C.51.

Hispania, LXI/2, núm. 208 (2001) 619-660 
aumentar el número de reuniones de esta institución, y se trató de introducir más vocales electivos en el seno de la Comisión del consejo, que funcionaba con carácter permanente y que actuaba al lado de los técnicos de la administración, una presencia que sin embargo quedará más reducida.

La campaña de los propietarios para formar parte del Consejo, llevó en primer lugar a la movilización de todas aquellas Cámaras Agrícolas constituidas, a las actividades en favor de determinadas candidaturas, y a la búsqueda del voto, en el seno de unas entidades dominadas en gran medida por sectores propietarios o labradores acomodados ${ }^{23}$, que iban a ser los encargados de elegir a los mediadores de intereses agrícolas en la administración, con unas candidaturas, ocupadas por élites, y manteniendo al margen de este proceso a la mayoría de la población agraria ${ }^{24}$. Un sistema electivo, que evidentemente no contribuía a crear ni mucho menos, "canales democráticos puros» o «aislados», del sistema de relaciones políticas dominante, sino que reproducían en su forma y fondo, las características esenciales de las representación política clientelar del sistema de la Restauración.

En este sentido, las consignas de los dirigentes agrarios en favor del voto hacia entidades agrarias locales, podían ser respetadas en general, cuando existía un lazo estrecho con la cámara local a la que se le exigía el voto ${ }^{25}$, o cuando aparecía la mediación de algún prócer local o provincial ${ }^{26}$ en favor de una determinada candidatura ${ }^{27}$. Sin embargo, esto no quiere decir que desde abajo existiese siempre una supeditación de las consignas marcadas por.los dirigentes agrarios. Esta nueva movilización en favor de candidaturas discurría en el seno de una sociedad rural, que comenzaba a organizar asociaciones interclasistas, dominadas por labradores y propietarios, y que además poseía sus propios mecanismos de intervención en la administración a través de sus diputados. En

23 SANZ Lafuente, G.: (1999) Organización y movilizaciones de propietarios agrarios en Aragón. Redes de intervención política, gestión comercial-crediticia y reproducción social. Tesis doctoral inédita. Departamento de Historia Moderna y Contemporánea. Universidad de Zaragoza. pag. 237-260/312-355.

${ }^{24}$ Sobre esta búsqueda de votos y las recomendaciones en la campaña de Tomas Costa, AHPH. Sección de Joaquin Costa. Carta del Conde de Torres Cabrera a Joaquin Costa, 1910. C.86.

${ }^{25}$ En este sentido, Tomás Costa como dirigente de la Federación de Castilla La Nueva recibía esta significativa misiva del presidente de la Cámara Agrícola de Ciudad Real. AHPH. Sección Joaquin Costa. Carta del Marques de Casa Treviño. Presidente de la Cámara agrícola de Ciudad Real a Tomás Costa. 1910. C.86. "En la sesión preparatoria celebrada hoy por la Junta Directiva de esta Cámara he propuesto su nombre para que figure en primer lugar en la candidatura para vocales del consejo Superior de Producción y ha sido aceptado unánimemente. En segundo lugar votaremos a D. Antonio Falcón Velasco de la Federación A. de Levante y como para los otros lugares no tenemos candidatos ni tampoco para suplentes y mañana tendrá lugar la elección, mucho le agradeceré que me indicase nombres de personas afectas a nuestra federación para que las pudiésemos votar».

${ }^{26}$ AHPH. Sección Joaquin Costa. Carta de Pedro Sánchez, presidente de la Cámara Agrícola de Arcos de La Frontera. 1910.C. 86.

${ }^{27}$ La actividad de la Cámara Agrícola de Zaragoza a favor de la candidatura de Tomás Costa y Francisco Bernad. AHPH. Sección Joaquin Costa. Carta de Enrique Sagols, presidente de la Cámara Agrícola de Zaragoza a Tomás Costa. 1910. C. 86. 
este sentido, los candidatos debieron llevar a cabo una campaña de propaganda en el seno de las cámaras agrícolas, defendiendo las ventajas de estos centros y mostrándose como los garantes de una representación de la Agricultura en general y de mediaciones concretas. Con todo, y en los comienzos de este proceso, estos propietarios tuvieron que competir en ocasiones con la desconfianza y la interpretación que los dirigentes de cámaras locales, hacían de estos cargos administrativos.

De esta forma, las candidaturas propuestas no eran aceptadas en otras entidades locales ${ }^{28}$, sino que desde estas se llegaban a realizar modificaciones propias introduciendo por ejemplo a representantes políticos locales o provinciales, que se consideraban el «eslabón propio» de intervención de una determinada comarca en estos nuevos organismos, que actuaban en estrecha relación con los espacios del poder central. Se trataba así de incluir entre los candidatos a las vías más directas de intervención supralocal que se conocían, y que ya operaban en estos municipios. Así por ejemplo, desde la Cámara Agrícola de Menorca, a la que Tomás Costa le había solicitado el voto se le comunicaba la inclusión de representantes propios, identificados con grandes hacendados ${ }^{29}$. Este hecho también se reiteraba por ejemplo en Barbastro (Huesca), con cuyos dirigentes tenía Tomas Costa relaciones personales, llegando a introducir también al Diputado Antonio Aura Boronat como candidato entre los dirigentes agrarios, "para estar a bien con él». Desde Barbastro se llegaba a pedir incluso información sobre el resto de candidatos, a los que consideraban «desconocidos» y respecto a los que no se sabía muy bien que «ayudas» se iba a recibir de los mismos ${ }^{30}$. La participación en este tipo de elecciones pasaba así por un filtro utilitarista propio, que hacía observar a los representantes elegidos como garantes de plurales intervenciones políticas, en manos de unos dirigentes agrarios locales, que en le caso de la Cámara Agrícola del Alto Aragón poseían estrechas conexiones con el ayuntamiento de Barbastro y que pretendían obtener así una nueva extensión de poder y de reconocimiento en el seno de su municipio. Los mecanismos asociativos dominados por los propietarios y sus sistemas electorales, distaban con mucho de contribuir así a una movilización de sectores agrarios amplios y ésta tampoco se realizaba en un sentido democrático sino reproduciendo las redes clientelares. Más bien, estuvieron destinados a fortalecer correas de transmisión en manos de dirigentes agrarios - propietarios y

\footnotetext{
${ }^{28}$ Algunas señalan por ejemplo, tener comprometido el voto para otros representantes de organizaciones agrarias. Tal era el caso de la Cámara de Espluga de Francoli con los representantes de la Federación Catalano Balear. AHPH. Sección Joaquin Costa. Carta de José Cabeza Presidente de la Cámara Oficial de Espluga de Francoli. 1910. C.86.. También, AHPH. Sección Joaquin Costa. Carta del presidente de la Federación Agraria de Levante, Manuel Iranzo Benedito a Tomás Costa. 1910. C.86. C.86.

${ }^{29}$ AHPH Sección Joaquin Costa. Carta del presidente de la Cámara Agrícola de Menorca. 1910.

30 AHPH Sección Joaquin Costa. Carta de Mariano Molina. Presidente de la Cámara Agrícola de Alto Aragón a Tomás Costa. 1910. C. 86.
}

Hispania, LXI/2, núm. 208 (2001) 619-660 
labradores acomodados-, que volvían a presentarse como las únicas vías de intervención por las que obligatoriamente debía pasar la actividad política de la sociedad agraria.

Desde abajo, además de restringirse en gran medida la votación a unas cámaras oficiales, que en el caso de Aragón, tenían un predominio de los sectores más altos de las cuotas contributivas entre sus dirigentes, la intervención en estas elecciones oscilaba entre el «desconocimiento sobre su utilidad», y la identificación de los apoyos otorgados a las diferentes candidaturas agrarias como vías de penetración en la labor de la administración, en defensa de plurales intereses locales o comarcales. Se consideraba así a estas instituciones como canales cercanos a los centros de poder y a los candidatos votados como garantes de esa misma participación. Unas vías de penetración, que sin embargo pasaban por la figura del dirigente local y de los grandes propietarios, contribuyendo a incrementar el poder de los grupos sociales agrarios que controlaban estas correas.

Desde la defensa de «intereses agrícolas regionales» ${ }^{31}$, hasta las actuaciones puntuales y concretas, pasando por las importantes subvenciones agrícolas, la correspondencia recibida por Tomas Costa muestra en este sentido, la utilización, que pretendía hacerse desde abajo de su voto. Marcelino Gambón, presidente de la Liga de Contribuyentes de la Ribagorza y miembro de la Cámara Agrícola del Alto Aragón, se dirigía ya en 1908 a Tomás Costa, para intentar recibir una subvención para la entidad agrícola, al ser éste Jefe provincial de Fomento de Toledo ${ }^{32}$. Mariano Molina, presidente de la Cámara Agrícola del Alto Aragón, también se dirigía a Tomás Costa en la búsqueda de una subvención de 1500 pesetas $^{33}$. En el mimo sentido, el presidente de la Cámara Agrícola de Zaragoza

\footnotetext{
31 AHPH. Sección Joaquin Costa. Carta de José María Ordeig, presidente de la Cámara Agrícola de Valencia a Tomás Costa. 1910. C. 86.

32 AHPH Sección Joaquin Costa. Carta de Marcelino Gambón a Tomás Costa. 1908. C.78. «...Mira de apretar a Besada par arrancarle la subvención. Interesa al señor Piniés de mi parte en este asunto..». En el mismo sentido, AHPH. Sección de Joaquin Costa. Carta de Marcelino Gambón a Tomas Costa. 1910. C. 80. «...ंno se podría conseguir una subvención, como otras sociedades, cámaras y ligas del Estado para nuestra liga o el periódico de 1000 pesetas?. En otras se ha conseguido....». La respuesta del ministro a Tomás Costa, AHPH. Sección Joaquin Costa. Carta de R. Gasset, Ministro de Fomento a Tomás Costa. 1911. C. 12 . «Mi querido amigo: A pesar de mi mejor deseo por servirle no me es posible acceder a su petición de que le sea concedida a la Cámara de Barbastro una subvención de 1000 pts, por estar agotada la consignación que figura en presupuesto para este objeto...». La remisión de instancias para ser tramitadas en Madrid sobre problemas locales AHPH. Sección Joaquin Costa. Carta de Marcelino Gambón a Tomás Costa. 1907. C.80.

33 AHPH. Sección Joaquin Costa. Carta de Mariano Molina a Tomás Costa. 1912. C.80. Así por ejemplo, este dirigente agrario de Barbastro señalaba: «...y esperamos que este año será concedida, a ver si podemos impulsar algo esto...le suplico a $\mathrm{V}$. que se interese con el ministerio de fomento para conseguirlo».
} 
se dirigía a éste, solicitando su mediación para conseguir una subvención para la entidad oficial ${ }^{34}$.

Las subvenciones a las organizaciones agrarias, que se concedían por el Ministerio de Fomento, establecían en primer lugar en el seno de cada una de las provincias, un primer elemento de mediación identificado con el Consejo Provincial de Fomento. Estos eran los encargados de informar las solicitudes que se dirigían a estos, por parte tanto de las grandes federaciones agrarias, como desde las cámaras oficiales y sindicatos agrícolas. Una vez que se había pasado la criba de unos consejos, cuyos cargos estaban ocupados por propietarios representantes de la burguesía agraria organizada a nivel provincial, estos se remitían al Ministerio donde de nuevo volvía a aparecer la mediación de los representantes de asociaciones agrarias en estas entidades consultivas. La labor en este sentido de Francisco Bernad Partagas, presidente por las mismas fechas de la Unión Agraria Española, y su intervención directa en las gestiones que llevaban a la distribución del montante entre las diferentes organizaciones agrarias, quedaba puesta de manifiesto cuando se dirigía a Tomás Costa en este sentido.

«...conforme a las indicaciones de usted, se borraron ayer las diferencias entre las federaciones proponiendo a todas para la misma cantidad, la de seis mil pesetas, incluso la aragonesa. No quise hubiera diferencias aún siendo tan justificada como la de presidir la Unión Agraria Española./ No me fue posible batallar por la de Escalonilla. El crédito para esa clase de entidades se había agotado y repartido antes de mi llegada a la Permanente ( $\mathrm{mi}$ ingreso como vocal), no habiendo términos hábiles para lograr lo deseado. Pero las seis mil de la Federación me figuro darán a V. medios para satisfacer esa legítima necesidad, según V. tuvo la bondad de explicarme. Alicante lleva dos mil pesetas y las demás cámaras una cantidad aceptable. Para otro año y si las cosas continúan del mismo modo e intervención nuestra, hay que tener una estadística me permita una distribución equitativa y más ajustada a verdaderas necesidades... ${ }^{35}$.

Las intervenciones solicitadas por los dirigentes de entidades locales no se limitaban sin embargo a su actividad de cara a la consecución de subvenciones, sino que abarcaban una pluralidad de tareas para sus nuevos intermediarios. Cuando se producía el nombramiento de Tomas Costa, éste era requerido por ejemplo para obtener relaciones comerciales con instituciones relacionadas con la distribución de productos escasos y de difícil acceso en el seno de los municipios oscenses, y respecto a los que todavía no funcionaban redes comerciales establecidas. En 1910 por ejemplo, Ruperto Sazatornil, miembro de la Liga de Contribuyentes de la Ribagorza, se dirigía a Tomás Costa solicitando la intervención de éste en el Instituto de San Isidro para obtener vacunas para el ganado,

${ }^{34}$ AHPH. Sección Joaquin Costa. Carta de Enrique Sagols, presidente de la Cámara Agrícola de Zaragoza a Tomás Costa. 1911. C.86.

35 AHPH. Sección Joaquin Costa. Carta de Francisco Bernad Partagas a Tomás Costa. 1911. C. 31.

Hispania, LXI/2, núm. 208 (2001) 619-660 
pidiéndole además información además sobre la fundación de una asociación de ganaderos para este fin ${ }^{36}$. En el mismo sentido, en 1912 y con motivo de la transformación legal de la Liga en Sindicato Agrícola, Marcelino Gambón le comunicaba a Tomás Costa la tramitación del expediente del Sindicato en el Ministerio de Fomento señalándole: «...haz que se apruebe pronto...» ${ }^{37}$. También se llegaba a proponer incluso desde la organización agraria local de Graus, el traspaso de los fondos del Pósito Municipal a las arcas de la Liga de Contribuyentes, a través de gestiones con el Delegado Regio de Pósito, para incrementar así el poder económico de la entidad en el seno del municipio. Una iniciativa ésta última, que finalmente no se llevaría a cabo $^{38}$. Mas adelante, también desde la Junta de la ALZ, se dirigían a Francisco Bernad en 1914, al haberse tenido noticia de la solicitud presentada por los cañeros andaluces para rebajar el impuesto de azúcares. Una propuesta considerada perjudicial para los intereses azucareros en Aragón y frente a la que se solicitarán «las gestiones» del propietario y abogado turolense "cerca de los poderes del Estado» 39 .

Las demandas locales abarcaban además otras «mediaciones», que se encontraban alejadas del funcionamiento de las entidades agrarias, y que incluían por ejemplo infraestructuras de una determinada comarca o municipio. Se trataba de utilizar así estos canales, para agilizar proyectos de obras públicas, que afectaban a la zona y también en ocasiones a intereses privados. Si en el caso de Graus, Marcelino Gambón le pedía a Tomás Costa que se interesara por la construcción de un puente en el municipio, Mariano Molina, presidente de la Cámara Agrícola del Alto Aragón, tras recordarle el voto favorable de la Cámara, le demandaba «el pronto despacho de la liquidación del primer trozo de carretera de Barbastro a Salas», con el fin de cobrar lo invertido como contratista ${ }^{40}$. Igualmente lo hacía de nuevo Marcelino Gambón, quien pedía a Tomás Costa se interesase sobre la inclusión de la carretera de Graus a Tremp en el nuevo Plan de Obras Públicas ${ }^{41}$.

Estos «representantes de la agricultura», identificados con grandes propietarios relacionados con poderosos entramados organizativos, como era el caso de la ALZ, se habían convertido en «mediadores» y «gestores», en relación con

\footnotetext{
${ }^{36}$ AHPH. Sección Joaquin Costa. Carta de Ruperto Sazatornil a Tomas Costa.1910. C. 80.

37 AHPH. Sección Joaquin Costa. Carta de Marcelino Gambón a Tomás Costa. 1912. C.13. Sobre la «congelación de la Ley de Sindicatos Agrícolas» y las dificultades para conseguir la aprobación de los expedientes en el Ministerio de Fomento. GARRIDO, S. (1994) «Alentar y obstruir. Las vacilaciones de la política estatal sobre cooperativismo en los inicios del siglo XX» en Noticiario de bistoria agraria, $\mathrm{n}^{\circ} 7$, en-jun, pag. 131-154.

${ }^{38}$ AHPH. Sección Joaquin Costa. Carta de Marcelino Gambón a Tomas Costa. 1911. C. 12.

39 BALZ, junio 1914. Sesión extraordinaria. Junta de Gobierno. 26-5-1914.

${ }^{40}$ AHPH. Sección Joaquin Costa. Carta de Marcelino Gambón a Tomás Costa. 1908. C.80. AHPH. Sección Joaquin Costa. Carta de Mariano Molina. Presidente de la Cámara Agrícola del Alto Aragón. 1910. C. 86.

${ }^{41}$ AHPH. Sección Joaquin Costa. Carta de Marcelino Gambón a Tomás Costa. 1911. C. 12.
} 
las demandas de entidades locales. Estas correas, depositadas por ley en sus manos, se convertían en mecanismos poderosos de consolidación y reproducción de su propio poder, sobre estas comunidades en las que se habían desarrollado cámaras agrícolas. Hacían así de si mismos, como representantes en órganos consultivos cercanos a los centros de decisión activa de la administración, una vía más de obtención de determinadas intervenciones políticas junto al diputado provincial o a Cortes, cooptando así y restringiendo al máximo, la formación de una sociedad civil en el campo, con capacidad para exigir derechos, y no gestiones o mediaciones clientelares.

Su presencia en estos órganos, no sólo le permitía a este grupo de la burguesía agraria «mediar», «intervenir»o «representar» en el más amplio sentido de la palabra, sino que los situaba como intérpretes privilegiados y únicos de la sociedad agraria, cuando informaban proyectos de ley o hacían propuestas concretas al gobierno. En este primer año por ejemplo, estos representantes agrarios en el Consejo demandaban la aplicación total de la ley de Sindicatos Agrícolas, se enfrentaban a las propuestas de reformas del catastro $0^{42}$, o pedían el incremento de la representación agrícola en la Junta de Aranceles y Valoraciones. Francisco Bernad llegaba incluso a lamentar en una carta a Tomas Costa, que «sólo» tuviera este Consejo Superior de Fomento un reconocimiento como institución consultiva, y comunicaba además el proceso de reuniones en la cumbre, que se producía entre los representantes de las grandes organizaciones en las oficinas de la Asociación General de Ganaderos del Reino, interesándose en la ocupación de cargos y gestiones diversas en la nueva entidad. Francisco Bernad concluía así: "Cierto, no cabe olvidar somos un cuerpo consultivo y todos nuestros deseos tienen el carácter de proposiciones, sin que esté obligado el Ministro a sujetarse a nuestras indicaciones, aunque éstas deben merecerle el natural respeto que su origen demanda» ${ }^{43}$.

A pesar de la instalación de los sectores agrarios en el consejo, pronto iban a surgir de nuevo las críticas por parte de propietarios hacia las escasas atribuciones consignadas al Consejo Superior frente a su antecesor. Se aludía así tanto a su inoperancia, como a la falta de atribuciones en relación con los sectores técnicos de la administración. La critica, secundada por la ALZ al formar parte por las mismas fechas de la Junta Directiva de la Asociación de Agricultores de España (AAE) tenía debajo la firma del futuro ministro de Fomento y presidente de la misma, el Vizconde de Eza. En clara oposición con estas ideas se encontraba la proposición elevada por la Asociación de Ingenieros Agrónomos. Este enfrentamiento representaba en primer lugar, las tensiones que provocaba el pro-

\footnotetext{
42 Las demandas se producían en un momento de discusión legal de los debates del siglo anterior, que llevaban finalmente a la gestión de un sistema catastral con la ley de 1906 y el reglamento de 1913, al que rápidamente se opondrán los propietarios organizados. «El avance catastral en al agonía de la Restauración (1906-1925)» en PRo RuIz, J.: ( 1992) Estado, geometría y propiedad. Los orígenes del catastro en España (1715-1941), Madrid, Ministerio de Economía y Hacienda. pag. 245-275.

43 AHPH. Sección Joaquin Costa. Carta de Francisco Bernad Partagas a Tomás Costa. 1911. C. 12.
} 
ceso de construcción de un aparato burocrático y administrativo de carácter técnico con los representantes de intereses económicos, en este caso agrícolas, que se oponían a cualquier tipo de reducción de sus vías de intervención, exigiendo órganos consultivos, a los que incluso intentaban dotar de capacidad supervisora respecto a la labor desarrollada por los grupos técnicos.

La demanda de la AAE redactada por el Vizconde de Eza, iba encaminada al restablecimiento del $\mathrm{RD}$ de 17-5-1907 en su integridad, suprimiendo las modificaciones que se habían realizado posteriormente, y que habían llevado en general, a marcar el carácter consultivo de estos organismos y a reducir algunas de las atribuciones que el primitivo decreto de 1907 concedía a los representantes de intereses agrarios, tanto en los Consejos Provinciales como en el Superior. En concreto, en 1907, se incluía entre las funciones de estos centros «la organización de servicios, las reformas legislativas y las de administración y de procedimientos», otorgándoles una amplia capacidad de iniciativa. Además de estos aspectos, se concedía participación en la dirección y vigilancia de los servicios administrativos de los cuerpos técnicos y como ya recogimos, una competencia plena en el reparto y adjudicación de premios y subvenciones. Frente a estas poderosas atribuciones, con la creación del Consejo Superior había desaparecido la capacidad de tutela administrativa. Las nuevas disposiciones de los años siguientes fueron restando incluso atribuciones a los sectores que accedían a estos entramados, tanto provinciales como centrales. Por ejemplo, en la concesión de subvenciones ${ }^{44}$ se reducía la labor a una comisión permanente minoritaria en el Consejo Superior, que era la verdadera encargada de ejercer ahora funciones exclusivamente consultivas. Frente a este proceso, el Vizconde de Eza reclamaba de la administración la vuelta al $\mathrm{RD}$ de 1907, una proposición que se consideraba central con el fin de que nuevas disposiciones, como las de enero de 1914, que incorporaba al Consejo Superior de Fomento la Junta de Colonización y Repoblación Interior, no se estableciesen en un marco que en realidad carecía de contenido gestor alguno ${ }^{45}$. Sus pretensiones eran mostradas como una iniciativa «en favor de la producción nacional» y rodeando las demandas de ideas como «descentralización» y «eficacia administrativa», a la vez que subrayaba también, la "conveniencia» para los intereses que representa$\mathrm{ba}^{46}$. En realidad, la AAE se había convertido en interlocutora de una burguesía agraria organizada, que buscaba mantener su capacidad de supervisión respecto a la actividad de la administración técnica.

${ }^{44}$ Sobre la supresión de la labor del Consejo Superior, en relación con las subvenciones y premios, aunque se mantenía la intervención de los Consejos Provinciales. RD 8-9-1912. Supresión del artículo 11 del $R D$ de 2-6-1911.

${ }_{45}$ Ver RD 2-1-1914. Incorporación al Consejo Superior de Fomento la Junta de Colonización y Repoblación Interior.

${ }^{46}$ AHPH. Sección Joaquin Costa. Copia mecanografiada de la propuesta elevada al Gobierno por Luis Marichalar y Monreal, Vizconde de Eza. Presidente de la Asociación de Agricultores de España. 14-11914. C.4. 
Frente a las pretensiones del Vizconde de Eza, se colocaba rápidamente la Asociación de Ingenieros Agrónomos, que se oponía con rotundidad a la vuelta al $\mathrm{RD}$ de 1907, aludiendo a la "perturbación» que habían causado en los servicios agronómicos las pretensiones de la AAE. Como cuerpo administrativo, «representante de la maquinaria política del Estado ${ }^{47}$ exponía así sus propios intereses, de cara a la configuración de funciones y al organigrama de la jerarquías. El prestigio adquirido por los sectores técnicos en el seno de la administración había ido forjando escalafones, funciones y competencias profesionales, que trataban así de ser defendidas. En realidad, en 1914 volvían a reiterarse los argumentos en contra que ya se habían expuesto en 1908, y que iban encaminados a separar totalmente la acción de los servicios agronómicos de la tutela de los centros consultivos. En este sentido, se señalaba como idea de base por parte del presidente de esta asociación que «es principio generalmente reconocido, lo mismo en el orden político que en el administrativo y económico, que las corporaciones o entidades deliberantes no tienen eficacia como ejecutivas, y así las funciones de mando y de consejo, propuesta y deliberación van siempre separadas.» Tras subrayar la defensa de los intereses "profesionales» de sus asociados, se intentaba apuntar a la necesaria "compenetración y definición de funciones» en el seno de la administración, y a la importancia de confiar la verdadera gestión a los sectores técnicos con una formación especializada, identificados en los servicios agronómicos, reduciendo las amplias funciones que se concedían a los consejos provinciales y de vigilancia, y a los jefes de fomento, ocupados por representantes de unas oligarquías locales sin formación técnica. En relación con estos organismos provinciales, que como veremos recogían a buena parte de la burguesía agraria organizada, se señalaba:

«Tanto los consejos provinciales como los de vigilancia....se verán con frecuencia en el caso de examinar o aprobar planos de experimentación y proyectos de carácter técnico para cuya censura carezcan de la necesaria preparación. Los Jefes de Fomento no son funcionarios retribuidos y no es probable que puedan dedicar el tiempo necesario de una manera continuada a los servicios que se les confía. Revestidos de una autoridad que no suele conseguirse sino después de detallados servicios, o de pruebas inequívocas de competencia, no ofrecen en general y salvo excepciones de todos conocidas, cuantas garantías de acierto fuera de desear en personas llamadas a desempeñar tan elevados cargos .... ${ }^{48}$.

En el mismo sentido, se aludía a aspectos concretos del funcionamiento de estas instituciones provinciales, como era el caso de la supervisión de los jefes de fomento respecto a las salidas de ingenieros agrónomos, o al necesario «visto bueno» del Jefe de Fomento Provincial en relación con los análisis de los labo-

\footnotetext{
47 Sobre la persecución de intereses propios por un creciente «funcionariado patrimonial», WEBER, M.: (1983) El trabajo intelectual como profesión, Barcelona, Bruguera.

$48 \mathrm{AHPH}$. Sección Joaquin Costa. Copia mecanografiada de la propuesta elevada al Gobierno por Vicente Alonso Marti.Presidente de la Asociación de Ingenieros Agrónomos. 16-2-1914. C.4. pag.3
}

Hispania, LXI/2, núm. 208 (2001) 619-660 
ratorios. Una capacidad, que para la Asociación de Ingenieros Agrónomos significaba por un lado, conceder funciones superiores y provocar «molestas subordinaciones» y por otra, dilación en la resolución de las mismas gestiones técnicas ${ }^{49}$. El comunicado aludía incluso a las «funestas consecuencias» que había ocasionado esta imbricación de unas élites agrarias, que dirigían los órganos consultivos, en las labores de la administración ejecutiva. Cuando el presidente de la Asociación llegaba a exponer como: «...fue preciso soportar resignadamente el menosprecio en que se tuvo nuestra dignidad profesional», intentaba además poner de manifiesto, la supeditación de los criterios técnicos de los agrónomos a los intereses o intervenciones de los «mediadores administrativos». Unos mediadores, identificados a escala provincial con unos propietarios vinculados a las organizaciones y cámaras oficiales, a las que se reconocía por ley la representación de los intereses agrarios en los consejos provinciales. Así, por ejemplo, si Francisco Bernad formaba parte del Consejo Superior de Fomento, por las mismas fechas Bernardo Zamboray lo hacia en el Consejo Provincial en representación de intereses agrarios. La conclusión de los ingenieros agrónomos no podía ser más clara y reflejar de mejor forma, las tensiones producidas con el despliegue de unas entidades burocráticas, entre unos intereses económicos provinciales con deseos de conservar capacidades de intervención o criterios de actuación, en definitiva Poder, en el seno de la administración. Al igual que sucedía en otras zonas, el ascenso de un novedoso profesionalismo funcionarial tenía como obstáculo tradiciones y poderes reservados a grupos de intereses locales ${ }^{50}$.

«...Convertir a los ingenieros agrónomos en meros ejecutores de los mandatos de los Consejos Provinciales y de los Jefes de Fomento es eximirles de responsabilidad y anular los conocimientos, que tienen adquiridos a expensas de la Nación

49 En concreto, el RD de 1907 al cuya vigencia pretendía volver la AAE señalaba: « Art. 6. Compete a los jefes de Fomento, como autoridad provincial superior en servicios de agricultura usar de la facultad concedida...a autorizar las salidas de los ingenieros agrónomos para ejecución de los servicios propios de sus cargo...» / "Art.7...Lo dispuesto en el artículo 33 del RD de 17 de mayo último respecto a la intervención del Jefe de Fomento y de los Consejos Provinciales de Agricultura y Ganadería en la dirección de los laboratorios agrícolas así como...se entienda ...de fundir las necesidades agrícolas de cada comarca con los servicios sostenidos por le Estado ...en forma que los planes, trabajos, experiencias y estudios realizados sean los que la representación de la propia agricultura crea más útiles y convenientes para el progreso general. /La dirección técnica y la ejecución agronómica de dichos planes y estudios corresponde a los ingenieros agrónomos, significando la ulterior aprobación por los respectivos Consejos de la labor realizada en cada centro...» Ver RD. 20-12-1907. Atribuciones y funciones de los Jefes de Fomento. Para Jordana de Pozas existía además un problema de definición de funciones políticas porque se quería arrancar a los gobernadores de la provincia facultades, que pasarían a formar parte de las atribuciones de los Jefes de Fomento. Unas disposiciones, que también contribuían a crear problemas. JORDANA DE POZAS, L.: (1961) Op. cit. pag. 459.

so Referencias a las demandas de sectores técnicos y a la lucha entre el profesionalismo y los grupos de intereses MALATESTA, M.: (1995) «The Italian professions from a comparative perspective» en MAlatesta, M.: (Ed.) Society and the professions in Italy, 1860-1914, Cambridge University Press. pag. 13. 
para el fomento de su riqueza. En resumen esta Asociación tiene la honra de exponer respetuosamente....se reserve a los ingenieros agrónomos la responsabilidad que debe exigírseles por sus conocimientos y por la tanto la independencia y libertad correlativas a su responsabilidad.../Los hechos Excmo. Sr. con su fuerza abrumadora vinieron a corroborar en la práctica los graves inconvenientes que ofrecían en su aplicación las disposiciones cuyo restablecimiento hoy se solicita por la Asociación General de Agricultores de España, imponiendo la necesidad de su derogación.... ${ }^{51}$.

Estas malas relaciones entre propietarios y técnicos de la administración agraria se veían matizadás a escala local y para el caso de Zaragoza, por la existencia de un sector profesional agronómico estrechamente relacionado con las organizaciones propietarias y con los hacendados que defendían una mayor capacidad de tutela administrativa. El saber científico de los técnicos mostraba pues a escala provincial, una estrecha relación con el poder social y económico de los propietarios gestores de las organizaciones agrarias en Zaragoza ${ }^{52}$. Los ingenieros agrónomos, en especial los de la Granja Escuela, mantuvieron en este sentido un «idilio» con organizaciones propietarias agrarias de cuyas juntas directivas llegarán a formar parte activa, como unos centros más - además de los oficiales - en los que desarrollar su actividad profesional. Si en los orígenes de las primeras asambleas de notables agrarios en el siglo XIX, los ingenieros agrónomos de la Granja eran habituales, su vinculación pasará a ser estrecha con la formación de las organizaciones. José Cruz Lapazarán, ingeniero jefe de la Sección Agronómica de Zaragoza en 1914 era vocal del SCA entre 1910 y 1913 y miembro de la Granja Escuela de Zaragoza. También desempeñará el cargo de secretario de la FAA en 1915 y de director del Boletín de la Federación Agraria Aragonesa. Manuel Gayán y Angulo, Ingeniero agrónomo en la Granja Escuela en 1910, era también vocal del SCA en 1909 y 1910. Más adelante, Joaquin de Pitarque y Elio, Ingeniero Agrónomo, profesor de la Granja Escuela, también será vocal del SCA en 1922 y uno de los ayudantes de este mismo centro, Francisco Guerra Salmón, se encargaba también del laboratorio de la ALZ. También, Mariano Lozano Colas será ingeniero subalterno de la Jefatura del Servicio Agronómico de la provincia, a la vez que miembro de la Junta de Gobierno de la ALZ 53

En esta visión regional de la historia social de la administración contemporánea ${ }^{54}$, el apoyo de la ALZ —el SCA todavía se encontraba en un segundo

51 AHPH. Sección Joaquin Costa. Copia mecanografiada de la propuesta elevada al Gobierno por Vicente Alonso Marti. Presidente de la Asociación de Ingenieros Agrónomos. 16-2-1914. C.4. pag.4.

52 Reflexiones interesantes sobre las relaciones entre propiedad y los profesionales agrónomos en Italia en MINESSO, M.: (1995) «The ingineering profession 1802-1923» en MALATESTA, M.: (Ed.) Society and the professions in Italy, 1860-1914, Cambridge University Press. esp. pag. 187.

53 EN, 8-1-1925. Nombramiento de ingenieros.

54 Ver por ejemplo sobre la necesidad de historiar las leyes desde el punto de vista social, Grossi, P.: (1986) (a cura di) Storia sociale e dimensione giuridica. Strumenti di indagine e ipotesi di lavo- 
plano-, a las propuestas de la AAE, representaba el interés mostrado por mantener un elevado grado de control, sancionado por ley, sobre la actividad de la administración todavía en 1914. Se trataba así de volver a la legislación de González Besada frente a las reformas de Fermin Cabeltón, tras el RD 7-101910, unas disposiciones, que desde la Federación Agraria de La Rioja se llegaron a denominar como "socialización de los servicios»". Aunque la ley se encargo de reconducir con titubeos una administración en sentido técnico, separando competencias, materias y funciones de inspección, y los consejos provinciales quedaran reducidos a cuerpos consultivos, el Comisario Regio de Fomento seguía teniendo consideración de Jefe Superior de la Administración Civil y se consignó a los centros provinciales la capacidad de informar las subvenciones a instituciones agrícolas, como veremos al estudiar el Consejo Provincial de Fomento de Zaragoza. La ALZ lograba mantener en este contexto la importante presencia de Francisco Bernad en los centros consultivos de la administración central.

Con ligeras modificaciones, se mantenía esta estructura hasta 1917 (RD. 68-1917), cuando de nuevo, y siendo ministro de Fomento Luis Marichalar, Vizconde de Eza, se promovía una reorganización de los servicios técnicos y sociales, subrayándose como objetivo en relación con el Consejo Superior la transformación de éste en una "verdadera asamblea agraria». Desde abajo se separaban a escala provincial los servicios técnicos de los consultivos, personificados ahora en los Consejos Provinciales de Agricultura y Ganadería, a los que sin embargo se reconocía funciones administrativas y sociales. Dentro de las primeras se incluían los servicios de estadística agrícola, la información de expedientes de vías pastoriles, de servidumbres rústicas y pecuarias y de aquellos relacionados con el cumplimiento sobre exenciones temporales de tributos o con el saneamiento de terrenos. También iban a tener facultades de inspección y coerción para extinguir plagas del campo y epizootias, organizando la enseñanza experimental y demostrativa agrícola provincial o la dirección de laboratorios provinciales.

Incluso, y en relación con las atribuciones consignadas al renovado servicio técnico provincial se subrayaba: «Para todas las funciones administrativas designadas en el capítulo $1^{\circ}$ de este Real Decreto el servicio técnico provincial

\footnotetext{
ro, Milano. Rubin, G. R.; Sugarman, D.: (1989) (Eds). Law, economy and society, 1750-1914. Essays in the History of the English law, Abingdon.

ss En este mismo sentido, la Federaciòn Agraria de La Rioja también solicitaba al Ministro de Fomento: «...la intervención de las Asociaciones agrícolas en el Consejo Superior de la Producción y del Comercio y en los Consejos provinciales de Fomento, tal como se la reconoció el Sr. González Besada en mayo de 1907 y que arbitrariamente se la han arrebatado los gobiernos liberales. La tendencia hacia la socialización de los servicios iniciada por aquel ministro y tan discreta y tenazmente secundada por el Vizconde de Eza es de perentoria necesidad si se quiere acabar con el convencionalismo burocrático y con el divorcio cada vez mayor que se está abriendo entre la Agricultura y el Ministerio...» AHPH Sección Joaquin Costa. Exposición mecanografiada de la Federación Agrícola de La Rioja al Ministro de Fomento. 2-1-1914. C.4.
}

Hispania, LXI/2, núm. 208 (2001) 619-660 
dependerá del Consejo Provincial a los efectos de unidad en el servicio». Unas atribuciones que excedían a las de los anteriores y que incorporaban a las asociaciones agrícolas ajenas al marco oficial de las Cámaras en su elección. Por encima se creaba sin embargo una estructura con representación de todos los consejos provinciales y de los servicios técnicos, que con sólo dos reuniones al año poseía ahora funciones de vigilancia respecto a los Consejos Provinciales, manteniendo la capacidad de proponer iniciativas relacionadas con el crédito o la cooperación. Era la respuesta del antiguo presidente de la Asociación de Agricultores de España a la construcción administrativa del Estado, que contará en 1920 con una nueva versión que restauraba los Consejos Provinciales de Fomento y el Consejo Superior con atribuciones similares a las anteriores a 1917, y que precedía a la organización corporativa de la Dictadura de Primo de Rivera, saludada tanto por la ALZ como por el SCA y la AAE. Era evidente, que el proceso de construcción de la administración distó con mucho de ser una labor aséptica y una expresión de leyes elaboradas en laboratorios ajenos a las relaciones económicas y de poder en las que se asentaban. Analizar esta profusa labor merecería sin embargo una profundidad que se aleja de las modestas pretensiones de esta primera aproximación.

Estos órganos consultivos de fomento no fueron sin embargo los únicos objetivos de los "propietarios organizados", los representantes de las organizaciones agrarias comenzaron a batallar por conseguir acrecentar la presencia de los autodenominados «representantes de los agricultores» en otros centros. Este será el caso de la Junta de Aranceles y Valoraciones, verdadero objetivo de los propietarios organizados, como institución relacionada con la gestión de los difíciles equilibrios de la política comercial. Entre las atribuciones de esta institución se encontraba la fijación, en el primer semestre de cada año, de los valores oficiales, que hubieran tenido las mercancías importadas y exportadas, con el fin de formar y publicar las tablas de dichas valoraciones. También informaba sobre todos proyectos de reforma general o parcial del arancel de aduanas, y elevaba por iniciativa propia los proyectos y propuestas relacionados con el arancel. Unas actividades, que hicieron de estas instituciones «centros deseados» por parte de los propietarios organizados. Cuando en 1898 se reorganizaba la Junta de Aranceles y Valoraciones (RD. 1-2-1898), en su composición aparecían como vocales natos instituciones como la Cámara de Comercio de Madrid, el Círculo de la Unión Mercantil de Madrid o Fomento del Trabajo Nacional de Barcelona, entidades relacionadas con la defensa de intereses comerciales e industriales. Al reorganizarse de nuevo el centro en 1910 (RD 11-10-1910) se incluía entre los vocales natos al presidente de la Liga Nacional de Productores, sin que apareciese entre estos cargos ninguna entidad agraria. Estos si que formaban parte sin embargo de los 63 vocales numerarios, de los cuales 14 correspondían a la agricultura y seis a la ganadería. Es en este contexto, en el que comienzan a desarrollarse las protestas de las organizaciones agrarias propietarias, que buscaban el reconocimiento de sus representantes como vocales natos y un incremento de los numerarios.

Hispania, LXI/2, núm. 208 (2001) 619-660 
De nuevo volvía a ser la Unión Agraria Española, la plataforma utilizada por los representantes de las principales federaciones y grandes organizaciones de carácter provincial, con el fin de aunar esfuerzos y ejercer las presiones tendentes a su reconocimiento como representantes de «la rama más importante de la producción nacional», como señalaba Tomás Costa ${ }^{56}$. Así, y haciendo uso de las prerrogativas que les concedía el propio reglamento del Consejo Superior de Fomento, los nuevos vocales realizaban una propuesta destinada a acrecentar el número de vocales representantes de la agricultura en la Junta, con el fin de que estos correspondiesen a la capacidad de tributación de este sector, y además su elección descansase sobre las nacientes organizaciones agrarias, consideradas como las «corporaciones legítimas» que los representaban ${ }^{57}$.

Esta proposición ${ }^{58}$, que ya había formado parte de las conclusiones del Congreso Agrícola de Zaragoza en $1910,{ }^{59}$ no respondía sin embargo a una ausencia de los intereses agrarios en el consejo, ya que estos habían estado representados con anterioridad, sino que formaba parte más bien, del intento de las novedosas organizaciones agrarias y de sus dirigentes propietarios, por cooptar esta representación e intentar acrecentarla en la medida de lo posible a través de sus asociaciones. Las dificultades y luchas entre los diversos sectores económicos por mantener una presencia en esta institución volvían a ponerse de manifiesto cuando Francisco Bernad subrayaba las oposiciones que se encontraban a que la agricultura tuviese una representación proporcionada a la cuantía de tributos que satisfacía, o al exponer la negativa a reconocer a los presidentes de las Federaciones Agrarias como vocales natos de la Junta de Aranceles y Valoraciones ${ }^{60}$. Los representantes de las grandes organizaciones propietarias del país se reunían así en el marco de la Unión Agraria, con el fin explícito de «ver sentar las líneas generales de criterio de la Unión Agraria en materia arancelaria» ${ }^{61}$

\footnotetext{
${ }^{56}$ AHPH. Sección Joaquin Costa. Proposición manuscrita de Tomas Costa al Consejo Superior de Fomento. (sin fechal posib.1911). C.31.

57 En este sentido, se señalaba la necesidad de «reorganizar por ley la actual constitución de la Junta de Aranceles y Valoraciones haciendo que en ella no haya otros vocales natos que los que representan a la administración y siendo todos los demás que la componen designados exclusivamente por los propietarios organizados en las corporaciones que legítimamente les representan.». EM, 27-8-1914. Llamamiento a los agricultores.

58 AHPH. Sección Joaquin Costa. Proposición manuscrita de Tomas Costa al Consejo Superior de Fomento. (sin fechal posib.1911). C.31.

59 DAZ, 12-10-1910. Congreso Agrícola de Zaragoza. Ponencia de Antonio Casaña. "Los aranceles y la agricultura». "Que la agricultura y la ganadería tengan en la Junta de Aranceles y Valoraciones representación adecuada a su importancia, es decir, proporcional a lo que satisfacen por cuota contributiva o a la valoración de sus productos, con relación a las demás fuentes de riqueza.»

60 AHPH. Sección Joaquin Costa. Carta de Francisco Bernad Partagas a Tomás Costa. 1911. C. 31.

${ }^{61}$ AHPH. Sección Joaquin Costa. Acta de reunión de la Unión Agraria Española. 3-5-1911. C.31.
} 
2. Representantes de organizaciones agrarias que forman parte de la Unión Agraria Española. 1911

\begin{tabular}{c|c}
\hline NOMBRE & ORGANIZACIÓN AGRARIA \\
\hline Jaume Maspons i Camarasa & Federación Catalano Balear \\
\hline Jorge Jordana Mompeón & Federación Agraria Aragonesa \\
\hline Tomas Costa Martínez & Federación Agraria de Castilla La Nueva \\
\hline Conde de Torres Cabrera & Federación Bético- Extremeña- Canaria \\
\hline Manuel Iranzo Benedito & Federación Agraria de Levante \\
\hline Duque de Bailen & Asociación General de Ganaderos del Reino \\
\hline
\end{tabular}

AHPH. Sección Joaquin Costa. Acta de la sesión de la Unión Agraria Española. 3-5-1911.

La Unión Agraria Española volvía a reunirse convocada por el Duque de Bailen en 1915, con el objetivo de reiterar el necesario incremento de la presencia de sus miembros en la Junta de Aranceles y Valoraciones, identificando la inclusión de los propietarios y de asociaciones con la representación de la "clase generale» agrícola «dentro del Estado». Jorge Jordana, presidente de la Casa de Ganaderos de Zaragoza y de la Federación Agraria Aragonesa y Francisco Bernad, presidente por estas fechas de la ALZ, eran los representantes aragoneses en la plataforma de las grandes organizaciones agrarias. Junto a estos, de nuevo aparecían dirigentes de las otras Federaciones como Pedro León de Castilla La Vieja, Antonio Costa de la de Castilla La Nueva, Ubaldo Fuentes de Valencia, J. Vidal y Barraquer y Juan Riba de la Catalano Balear y el Marques de la Frontera en representación de la Asociación de General de Ganaderos del Reino. En la reunión se consideraba entre otros temas, que la constitución de la Junta de Aranceles en 1910 no se había realizado con «la debida proporcionalidad», y que las representaciones no ofrecían «la debida garantía», para concluir en este sentido: «...es urgentísima e indispensable su reforma por RD proponiendo como vocales natos de la misma a los presidentes de la Asociación General de Ganaderos del Reino y de la Unión Agraria Española, nombrándose los numerarios a propuesta de los sindicatos agrícolas, convocados por las Federaciones Agrícolas Regionales, que integran la nombrada Unión Agraria, donde estén legalmente constituidas» ${ }^{62}$.

La Junta, que desde su fundación iba a estar sometida a continuas modificaciones y la campaña de la Unión Agraria llevaban finalmente, no tanto a reconocer el peso de los agrarios en relación con la tributación satisfecha como se demandaba en 1911, pero si a incrementar la presencia en la institución como representantes de la nuevas organizaciones agrarias y a un reconocimiento de la Unión Agraria Española, como plataforma de intereses de las principales

${ }^{62}$ ER, 3-8-1915. La Unión Agraria Española. 
federaciones. Cuando en 1917 ( RD 9-6-1917) se volvía a reorganizar la institución, los centros agrarios que iban a poseer representación eran la Unión Agraria Española, que había protagonizado junto a otros la campaña, el IACSI, cuyos representantes tenían ahora una representación propia como vocales natos en representación de los propietarios agrarios catalanes, la AAE y la Asociación General de Ganaderos del Reino. Junto a estos iban a aparecer también vocales numerarios ${ }^{63}$, en cuya elección se reconocía ya además de las cámaras oficiales, a las Federaciones Agrícolas y Asociaciones de Labradores. Con ligeras modificaciones, se producía una repetición de la representación en 1919 (RD 2-11919), si bien se producía una reducción dentro de los vocales numerarios elegidos por los organismos agrarios, que contaban con 7 representantes frente a los nueve de los centros industriales y comerciales.

Desde la ALZ, como principal organización agraria de carácter propietario, se intentaba ya en 1914 realizar gestiones con el objetivo de situar a sus dirigentes en los centros relacionados con la administración del Estado. En este sentido, en 1913 se subrayaba desde la Junta Directiva, la necesidad de apoyar «cerca del excelentísimo señor ministro de Hacienda la designación del señor Manuel Marraco para formar parte como vocal de la Junta de Aranceles y Valoraciones» ${ }^{64}$. Al año siguiente se producía la designación de éste como vocal, celebrándose desde la asociación la posibilidad de contar con una nueva correa de transmisión en relación con las instituciones centrales. El nombramiento acrecentaba así la presencia de los representantes de la ALZ en los espacios relacionados con la administración, uniéndose ahora a la figura de Francisco Bernad Partagas la de Manuel Marraco, en el seno de un nuevo centro65.

Esta presencia se iba a intentar mantener en la medida de lo posible. Sin embargo, en el seno de la provincia y a medida que se desarrollaba la Confederación Nacional Católico Agraria, se iba a producir un proceso de lucha entre los propietarios católicos y los hacendados "laicos» de la ALZ, destinado a extender su capacidad de acción en estas instituciones. Cuando se organizaba la Confederación, entre las ocho conclusiones que acompañaban a la asamblea de 1917 tres estaban relacionadas con la representación de la agricultura. En ellas se demandaba de nuevo, que el número de representantes en la Junta de Aranceles y Valoraciones y en el Consejo Superior y Provincial de Fomento fuera proporcional a la cuota contributiva de cada ramo, exigiendo una participación mayor de las asociaciones no oficiales para elegir a los representantes ${ }^{66}$.

\footnotetext{
${ }^{63}$ Dentro de los vocales electivos, nueve eran designados por las Cámaras Oficiales Agrícolas, asociaciones de labradores y federaciones agrarias. Otros nueve eran elegidos por las Cámaras Oficiales de Industria, Comercio y Navegación y doce de libre elección por el Gobierno. (RD. 8-61917)

${ }^{64}$ BALZ, noviembre 1913. Sesión ordinaria 7-10-1913.

65 BALZ, septiembre 1914. Junta de Aranceles y Valoraciones.

${ }^{66}$ EN, 21-4-1917. Asamblea de la Confederación Nacional Católico Agraria.
}

Hispania, LXI/2, núm. 208 (2001) 619-660 
A partir de 1919, en las nuevas elecciones para la Junta de Aranceles, la Asociación de Agricultores de España, en la que estaba integrada la ALZ, y la CNCA proponían una candidatura conjunta dirigiéndose desde el católico Sindicato Central instrucciones a los sindicatos locales para las votaciones. Como miembros de la candidatura vencedora se encontraban Francisco Bernad, presidente de la ALZ y José María Azara del SCA ${ }^{67}$. En 1921, José María Azara, vicepresidente ya de la CNCA, promovía una campaña de movilización entre los sindicatos locales con el fin de obtener su elección con miembro en la Junta de Aranceles. Finalmente, tras actividades propagandísticas en los municipios y recomendaciones sobre la forma de llevar acabo los votos salía elegido de nuevo como vocal. Con todo, la presencia de los dirigentes de la ALZ, no parece que se redujese sino que se mantenía. Así, en 1922 y con motivo de la elección de miembros de las entidades agrícolas como vocales electivos, Francisco Bernad Partagas, era elegido en primer lugar, como representante en este centro ${ }^{68}$.

\section{Propietarios-dirigentes agrarios aragoneses que participan en la Junta de} Aranceles y Valoraciones y en el Consejo de Economía Nacional. 1914-1929

\begin{tabular}{c|c|c}
\hline NOMBRE & ENTIDAD & FECHA ELECC. \\
\hline Manuel Marraco Ramón & Asociación de Labradores de Zaragoza & 1914 \\
\hline Francisco Bernad Partagas & Asociación de Labradores de Zaragoza & 1921 \\
\hline José María Azara Vicente & Sindicato Central de Aragón & 1921 \\
\hline Francisco Bernad Partagas & Asociación Labradores de Zaragoza & 1929 \\
\hline
\end{tabular}

Fuentes: BALZ, septiembre 1914. Memoria ALZ, 1922-23. BALZ, febrero 1929

Más adelante, durante el periodo de la Dictadura de Primo de Rivera, en el que trató de exprimirse al máximo el corporativismo en el seno de la administración, mediatizado sin embargo por unas reformas circunscritas a un periodo de tiempo reducido, se creaba momentáneamente el Consejo de la Economía $\mathrm{Na}$ cional $^{69}$ ( $\mathrm{RD} 8$ 8-3-1924), que asumía todas funciones referentes a la formación

67 EN, 26-1-1919. Para la Junta de Aranceles.

${ }^{68}$ A.L.Z (1923) Memoria...Op. cit. pag. 9.

${ }^{69}$ Los trigueros movilizados por estas fechas, apuntaban a la necesidad de intervenir en estas instituciones como nuevos centros de negociación de los sectores económicos. Así por ejemplo, se señalaba: «...En vista de que el actual gobierno admite como legítima y conveniente la intervención oficial en la política arancelaria de asociaciones de industriales organizados para sus exclusiva protección, los productores y transformadores de trigos...piden puesto en el Comité Permanente del Consejo de Economía para poder defender sus derechos legítimos ante los ataques insistentes de la molinería del litoral, que no teniendo producción propia que transformar, aspira a ser puerta abierta siempre abierta al extranjero.» EN, 26-4-1924. Magna asamblea de los trigueros aragoneses en la Lonja. 
de los aranceles o a la gestión de convenios comerciales, quedando suprimidas instituciones anteriores ${ }^{70}$. En relación con la agricultura, la institución se convertía en un centro con representación de múltiples asociaciones relacionadas con producciones sectoriales agrícolas, a las que se intentaba introducir en el marco oficial. Desde la Asociación Nacional de Olivareros, pasando por la $\mathrm{CNCA}^{71}$, la ALZ o el IACSI, se intentaba "conceder representaciones corporativas en el Consejo» al mayor número de entidades posibles. Unas disposiciones, saludadas por la ALZ, que llegaba a proponer su propio proyecto de organización corporativa de la agricultura, en clara sintonía con las disposiciones del gobierno de la Dictadura ${ }^{72}$.

En medio de una exaltación del espíritu corporativo, que será señalado como el deseo supremo tanto de dirigentes de la ALZ como del SCA ${ }^{73}$, los propietarios organizados seguían manteniendo su actuación el seno de estas instituciones, intentando convertir la "corporación» en único mecanismo de reivindicación agraria y en definitiva en una estrategia más de mediación y dominio propietario ${ }^{74}$. Francisco Bernad Partagas resumía así en la Junta General de la ALZ, las actividades en la Sección de Aranceles del Consejo de Economía Nacional en su calidad de vocal, «las duras negociaciones en los tratados comerciales» o «las medidas que afectaban al cultivo de la remolacha», en un periodo de incremento de la intervención del Estado en el sector azucarero ${ }^{75}$. Un cargo el suyo, al que sumaba también su presencia como vocal en la Comisión Mixta Agrícola en 1930.

70 Entre las instituciones que se suprimían además de la Junta de Aranceles y Valoraciones se encontraba una pluralidad de centros relacionados también con la gestión de la política comercial. Estos organismos eran la Comisión Protectora de la Producción Nacional, el Centro de Información Comercial del Ministerio de Estado, la Sección de Estudios Arancelarios y Estadísticos de la Dirección General y Aduanas, el Negociado de Comercio Exterior y Asesoría Técnica de Comercio del Ministerio de Trabajo, Comercio e Industria, la Comisión para el estudio y preparación de Convenios de Comercio y el Instituto de Comercio e Industria. (RD. 8-3-1924).

${ }^{71} \mathrm{La}$ búsqueda del reconocimiento organizativo de los católico agrarios, como representante de la Agricultura en el marco de la Dictadura, EL, 30-10-1923. Comunicado de la Confederación Católico Agraria al presidente del Directorio Militar.

72 BALZ, junio 1928/ julio 1928. La organización corporativa de la agricultura.

73 Ver por ejemplo del dirigente de la Unión de Remolacheros y miembro del SCA. HUESO BALLESTER, José María: (1928) Organización corporativa de la agricultura, Zaragoza. También otro de los dirigentes del catolicismo social agrario, subrayaba más adelante su admiración hacia los «balbuceos corporativos» de la Dictadura de Primo de Rivera, retomando las ideas de Severino Aznar. SANCHO IZQUIERDO, M.: (1937) Corporativismo. Los movimientos nacionales contemporáneos. Causas y realizaciones. Zaragoza, Editorial Imperio. pag. 166-171. Las primeras aproximaciones en este sentido, a la necesaria «representación profesional» como forma de destrucción de la «lucha de clases» en LAS, diciembre 1916./ EN, 8-11-1916. Conferencia de Severino Aznar en el Ateneo de Zaragoza. El régimen corporativo.

${ }^{74}$ Sobre la consideración del corpotativismo como una forma de dominación social, CROUCH, C.: (1981) «Strategie di dominio: alcuni tipi ideali» en ( a cura di M. MAZAFFI) La società neocorporativa, Bologna.

75 BALZ, febrero 1929. Consejo de Economía Nacional. 
Aunque con toda seguridad, esta aproximación constituye una pequeñísima muestra, cuya trayectoria hay que estudiar en profundidad, el interés por ocupar e intervenir en los órganos de la administración fue un hecho reiterado en la vida de la gran organización agraria aragonesa. En ocasiones, este interés abarcó una gran heterogeneidad de centros. Entre otros, el propio Consejo del Banco de España, donde también la nueva Ley de Ordenación Bancaria (29-121921), reconoció a las organizaciones agrarias la capacidad de elegir a un representante. En 1922 sería José María Azara ${ }^{76}$, tras una campaña con apoyo de la Confederación Nacional Católico Agraria (CNCA) en todo el país, el encargado de ocupar este cargo ${ }^{77}$. Una presencia, que tenía además el soporte económico crediticio que rodeó a las grandes organizaciones agrarias y a la propia CNCA, que contó por ejemplo con el Banco Agrícola y Comercial, en cuyo consejo de administración se encontraba también el propietario católico oscense, y con cajas de ahorros y crédito propias, que buscaban un lugar en el seno de los entramados financieros. Más adelante, volvería a movilizarse a los sindicatos agrícolas, esta vez para la representación de la Junta Central de Colonización y Repoblación Interior (RO, 24-6-1925), con el fin de seguir ocupando todas aquellas instituciones, que dirimían intereses económicos agrarios. Todo ello, en medio de elecciones locales, que como en el caso de la Federación Católica de Tarazona o del Sindicato Agrícola de Los Fayos, se reducían a que la Junta Directiva rellenase el acta con los nombres propuestos de antemano desde Zaragoza o Madrid, al margen de los asociados, y buscando a cambio la contrapartida de la relación con un poderoso centro de intervención agraria exterior a la comunidad ${ }^{78}$.

Por debajo de esta enmarañada tela de representaciones y elecciones de mediadores agrarios, en el ámbito de la provincia existió también, una preocupación más que reiterada por utilizar los canales de representación ofrecidos por ley en instituciones como los consejos provinciales. Estos, que recogían a los propietarios dirigentes de las principales organizaciones agrarias, también formaron parte, como vimos, de las demandas expuestas por los grandes hacendados, con el interés de mantener desde la base, las competencias de estas entidades consultivas. En el siguiente punto, intentaremos recoger así la labor y la presencia de los dirigentes agrarios de la ALZ y del SCA en el seno se este centro, así como el proceso de acumulación de poder en el seno de los propietarios organizados, a través de redes de representación institucional en estos centros administrativos.

76 EL, 11-10-1922. Consejo del Banco de España. EN, 25-10-1922. Entrevista con José María Azara tras el triunfo en las elecciones del Consejo del Banco de España.

77 Sobre la lucha entre candidatos y la utilización de las cámaras agrícolas e instituciones locales en la votación, Boletín del Sindicato Agrícola Católico de Tauste, 1-11-1922. Elección de un vocal consejero del Banco de España.

78 ACSAT. Libro de actas de la Federación Católica de Tarazona, 17-6-1925. APJR. Libro de actas del Sindicato Agrícola Católico de Los Fayos. Sesión 24-11-1924. Con una decisión unilateral tomada por los dirigentes, la Junta del Sindicato de Borja también se limitaba a votar la candidatura del SCA, con quien mantenía relaciones comerciales. ASCB. Libro de actas. Sesión 24-6-1925.

Hispania, LXI/2, núm. 208 (2001) 619-660 
2. LA GESTIÓN CONSUlTIVA DEL ESTADO «DESDE ABAJO». LOS PROPIETARIOS ORGANIZADOS Y LAS INSTITUCIONES ADMINISTRATIVAS PROVINCIALES DE FOMENTO.

En el ámbito provincial, el proceso de burocratización también contaba con muestras institucionales propias, que en relación con la administración de Fomento tenía su expresión tras las reformas de principios de siglo en los Consejos Provinciales de Fomento. Estos constituían un punto de reunión entre los representantes de una administración técnica, con su expresión máxima en el Servicio Agronómico y las corporaciones de intereses privados, que contaban con sus ejemplos en cada una de las provincias. Se trataba así de centros oficiales, encargados de mediar en los servicios públicos de fomento en relación con la agricultura, la industria y el comercio. Su instauración, en medio de un creciente desarrollo de las organizaciones agrarias, solía rodearse de una asepsia, que solía esconder convenientemente los verdaderos juegos de fuerzas, los intereses económicos, las relaciones de poder y sobre todo la patrimonialización de estas entidades por parte de un grupo reducido con elevada continuidad. Cuando en 1907 se creaba el Consejo Provincial, y alentado por las iniciales atribuciones otorgadas a estos, desde la Liga Agraria se llegaba a observar a estas entidades como motor de "grandes transformaciones en la agricultura", como "destructores de caciquismo» o como mecanismo para «distribuir bien las fuerzas económicas en las provincias» ${ }^{79}$. La realidad sin embargo, iba a distar bastante de estos deseos grandilocuentes al convertirse en una nueva reproducción del poder agrario provincial en estos organismos.

Con una situación institucional heterogénea, que era modificada en numerosas ocasiones a lo largo del siglo, pero con un armazón fijo, que favorecía las relaciones entre los diversos intereses sectoriales y el Estado a través de representantes delegados, se creaba ya en 1907 unos Consejos Provinciales de Agricultura y Ganadería con grandes atribuciones en sus cometidos, reducidas como ya señalamos en posteriores entramados legales. A estos les sucedían en 1910 los Consejos Provinciales de Fomento, que serán con ligeras modificaciones los que se mantendrán en el tiempo durante el periodo que nos ocupa.

Atendiendo a esta disposición legal, en cada capital de provincia había un Comisario Regio nombrado por decreto. Junto estos, había una serie de vocales, elegidos cuatro de ellos por las cámaras agrícolas, que volvían a ser reconocidas por la administración oficial como canales privilegiados frente a las asociaciones privadas, dos por las cámaras de comercio, dos por las sociedades industriales, uno por las de navegación, uno por la Asociación de Ganaderos, uno por la Sociedad Económica de Amigos de País y otro por las Cámaras de propiedad. Como vocales natos aparecían los representantes técnicos de la administración y de la política provincial. Entre estos se encontraban el vicepresidente de la

79 LLA, 28-6-1907. Consejos Provinciales de Fomento. 
Comisión Permanente de la Diputación Provincial, el Ingeniero Jefe de Caminos Canales y Puertos, el Ingeniero de Montes, de Minas y el agrónomo, el Inspector de Higiene y Sanidad Pecuaria y el Visitador de Ganaderías y Cañadas. Un cargo este último, ostentado siempre por algún miembro de la Asociación Casa de Ganaderos de Zaragoza. Estos sectores técnicos como ha señalado María MALATESTA poseían un amplio margen de acción en la gestión de intereses locales, al organizar recursos que les eran otorgados por el estado central y pasaban a formar así parte de las redes relacionales de la burguesía agraria organizada en la capital provincial ${ }^{80}$. Unas relaciones, constadas igualmente en el caso de Huesca y de Teruel, donde también existían vínculos entre la propiedad organizada de la ALGAA y de la FTSAC con sus respectivos consejos provinciales.

Estos consejos eran los encargados de informar al Gobierno, al Gobernador Civil, Diputación Provincial y Ayuntamientos, en relación con asuntos relacionados con la agricultura o la ganadería y la industria, proponiendo al Consejo Superior cuanto considerase oportuno para llevar a cabo proyectos legislativos. Unas actividades, complementadas con la capacidad de informar las subvenciones solicitadas por las entidades agrarias locales al Ministerio de Fomento o con la de valorar proyectos relacionados con aprovechamientos de aguas, o la propia constitución y modificación de ordenanzas de comunidades de regantes. Además, estas instituciones estarán relacionadas con la difusión de los sindicatos y organizaciones agrícolas en el campo, y con la divulgación de temas agronómicos.

La financiación de la entidad, aunque recibía créditos del Gobierno con el fin de atender a los gastos de los posibles congresos o exposiciones que pudiera organizar $^{81}$, se conseguía además con las cantidades que las Diputaciones provinciales consignaban en sus presupuestos. No obstante, estas donaciones económicas no parece que se establecieran con regularidad, teniendo que acudir el Gobierno a dictar nuevas disposiciones en 1915 instando a las Diputaciones a cumplir con su deber ${ }^{82}$. Unos elementos, que redujeron la actividad de estas instituciones acusadas a veces de «inactividad» o de ser simples «ambiciones de la administración central» ${ }^{83}$, pero que situaron su labor, en manos de la oligarquía agraria zaragozana organizada, que era la encargada además de orientar hacia donde debían dirigirse su actividad ${ }^{84}$. Como grupo asentado sobre gran-

${ }^{80}$ MAlatesta, M.: (1995) «The Italian professions from a comparative perspective» en MALATESTA, M. (Ed.) Society and the professions in Italy, 1860-1914, Cambridge University Press. pag. 16. También, MeLIS, G.: (1988) Due modelli di amministrazione tra liberalismo e fascismo. Burocrazie tradizionali e nouvi apparati, Rome.

81 Ver Orden 27-9-1909. Dirección General de Agricultura Industria y Comercio.

82 RO, 22-4-1915. Consejos Provinciales de Fomento.

83 JORDANA DE POZAS, L.: (1961) Op. cit. pag. 458.

${ }_{84}$ Ya en 1907 el Conde de Retamoso señalaba a Tomas Costa: «Los consejos provinciales, así como los jefes de Fomento se encuentran en un periodo de dudas y vacilaciones en su constitución, sin medios económicos para su desarrollar sus gestiones, ni para material, oficinas, personal, viajes de apostolado social etc etc: faltos de instrucciones concretas que en una palabra andamos a ciegas.

Hispania, LXI/2, núm. 208 (2001) 619-660 
des patrimonios y organizado, generaban mediante este nuevo centro medios muy superiores al de otros sectores sociales para influir en su actuación y además, su presencia en ellos otorgaba poderes representativos privilegiados, «monopolistas» ${ }^{85}$, a una clase con capacidad para tomar decisiones vinculantes para la totalidad de la sociedad agraria a la que decían representar.

Baste como ejemplo de estas actividades, la capacidad de los Consejos para informar iniciativas legales como los posibles proyectos de ley, y las comunicaciones entre Tomás Costa, Jefe Provincial de Fomento de Toledo, y Antonio Casaña, Jefe Provincial de Fomento de Zaragoza, sobre la posibilidad de la implantación de la ley de accidentes de trabajo en el campo. La negativa del propietario de Caspe y vicepresidente al año siguiente del SCA a informar favorablemente la iniciativa legislativa, se acompañaba de una más que significativa exposición, que mostraba una curiosa distinción entre «mercedes» concedidas por voluntad los propietarios y «derechos» sancionados por ley. En relación con la legislación social, la posición de Antonio Casaña se situaba así más cerca de la caridad que del reconocimiento de derechos. Una posición, que formará parte del discurso de los propietarios agrarios, que no estuvo protagonizado por las cuestiones sociales en sus numerosas asambleas agrarias ${ }^{86}$.

Aunque su labor proponiendo o bien oponiéndose a iniciativas legales, no podemos analizarla en profundidad, si que podemos establecer en que grupos descansaba la labor de estos órganos consultivos, y también algunas de sus actividades. ¿Quiénes fueron en este sentido los sectores sociales agrarios que ocuparon estas entidades?, y ¿qué relaciones mantuvieron con las organizaciones agrarias?. En un principio, ya en 1907 Antonio Casaña se ponía en contacto con la Junta Directiva de la ALZ a fin de que designase a un representante para formar parte del Consejo Provincial siendo elegido Alejandro Palomar Mur. En realidad, la presencia de algunos de los promotores de organizaciones agrarias no era inaugurada por estas disposiciones legales, ni tampoco suponía en principio un cambio respecto a los sectores sociales agrarios que habían formado parte de estas instituciones anteriormente. En 1893 propietarios como Mariano Gómez Guallar y el Barón de la Linde formaban parte del Consejo Provincial de Agricultura y en 1897 la composición propietaria no ofrecía dudas, al formar parte de la institución Basilio Paraiso, Francisco Pascual, Justo Almerge, Miguel Hipólito de Val, y dos de los futuros hacendados relacionados con organizaciones agrarias como Joaquin de Ena y Jorge Jordana ${ }^{87}$. Algo simi-

\footnotetext{
V. que es gran amigo del Vizconde de Eza y además vocal del consejo superior sería muy importante tratara estos asuntos...» AHPH. Sección Joaquin Costa. Carta del Conde de Retamoso, Delegado Regio de Pósitos a Tomás Costa. 1907. C.15.

85 OfFE, C.: (1998) "Algunas consideraciones escépticas sobre la maleabilidad de las instituciones representativas» Zona Abierta, 84/85, pag. 123-146. esp. 128/132

86 AHPH. Sección Joaquin Costa. Carta de Antonio Casaña. Jefe Provincial de Fomento y Presidente del Consejo de Agricultura y Ganadería de Zaragoza a Tomás Costa. 1909. C.64.

87 LD, 9-11-1893/28-1-1897. Consejo Provincial de Agricultura.
} 
lar ocurre, si observamos quienes eran los Comisarios Regios de Fomento en Huesca, Zaragoza y Teruel. A Antonio Casaña se unían otros propietarios significados como eran Santos Naya en el caso de Huesca y Julián Santa Pau en Teruel. Incluso algunos, como Domingo del Cacho Floria en Huesca, iban a mantener su presencia desde finales del siglo XIX hasta $1910^{88}$. En sus comienzos, y ante la debilidad de los entramados asociativos agrarios en Huesca y Teruel, los cargos podían ser ocupados por sectores designados por los gobernadores entre los propietarios locales. Sin embargo, en el caso de Zaragoza, el desarrollo de las organizaciones agrarias permitió que se produjese una total imbricación entre la burguesía agraria organizada y los cargos del Consejo Provincial de Fomento desde principios de siglo.

Hacía 1914 los componentes del Consejo formaban parte de las Juntas Directivas, tanto del SCA como de la ALZ. Aunque desde el Gobierno prevalecía el interés por convertir a las Cámaras oficiales en los canales de representación agrícola, el proceso de cooptación progresivo de este centro de Zaragoza por parte de las entidades privadas, llevó a que desde abajo se identificara a los sectores que formaban parte de ambas instituciones en gran medida, y a que además, independientemente de su filiación organizativa o ideológica, todos ellos perteneciesen a la burguesía propietaria de los mayores contribuyentes. Como representantes de la Cámara Agrícola aparecía así Enrique Sagols, Casaña por su parte, era miembro por estas fechas de la directiva del SCA, Sabino Bea, propietario de Agón, también estaba vinculado al SCA y Bernardo Zamboray a la ALZ. Junto a estos, aparecía incluso otro propietario en representación de la Asociación General de Ganaderos del Reino, como José María Vargas Lavigne, dirigente de la Casa de Ganaderos de Zaragoza y Mariano Gómez Guallar, en representación de la Sociedad Económica Aragonesa de Amigos del País, y relacionado posteriormente con la Directiva del SCA. Incluso en representación de la Cámara de Comercio se encontraban Mariano Marraco y Joaquin Bielsa, ambos de la $A L Z^{89}$. Todos formaban parte del grupo «católico» y del «laico», con sus instituciones y correas políticas afines, y tenían al frente a un hacendado que poseía un importante «don de la ubicuidad» en el seno del heterogéneo grupo de intervención agraria zaragozano: Juan Fabiani Díaz de Cabria. Una presencia la suya al frente de la institución de larga duración, al extenderse al menos hasta 1922.

${ }^{88}$ LLA, 28-6-1907. Comisarios Regios de Fomento. EDH, 126-4-1892. Consejo Provincial de Agricultura. EDH, 10-12-1910. Consejo Provincial de Fomento.

89 CONSEjo PRovincial DE FOMENTO DE ZARAGOZA, (1914) Memoria general de los trabajos realizados desde su constitución hasta junio de 1914, Zaragoza, Imp. Heraldo de Aragón. pag. 3-4.

Hispania, LXI/2, núm. 208 (2001) 619-660 
4. Distribución y filiación asociativa de los miembros de Consejo Provincial de Fomento de Zaragoza. 1922.

\begin{tabular}{|c|c|c|c|}
\hline NOMBRE & CARGO & ENTIDAD OFICIAL & ENTIDAD \\
\hline Juan Fabiani Díaz de Cabria & Pres. & - & ALZ.V./CGZ.V.1922 \\
\hline Manuel Pérez Cistué & Vicepres. & - & CGZ.VP.1922 \\
\hline José Cruz Lapazarán & Secret. & Ingeniero Jefe serv. agron. & - \\
\hline Publio F. Coderque & Secret. & Inspector de Higiene y san. pec & - \\
\hline sd & Vocal. nato & Ingeniero Jefe obras Públicas & - \\
\hline sd & Vocal. nato & Ingeniero Jefe servicio Forestal & - \\
\hline sd & Vocal. nato & Ingeniero Jefe de minas & - \\
\hline Mariano Pin Novella & Vocal. nato & representante de la Diputación & - \\
\hline Celestino Archanco & Vocal. nato & $\begin{array}{l}\text { Ingeniero indust depend } \\
\text { M. Foment. }\end{array}$ & - \\
\hline Jorge Jordana Mompeón & Vocal. nato & Visitador de ganaderías y cañadas & CGZ.P.1922 \\
\hline Genaro Poza Ibañez & Vocal elect. & - & CAZ.V.1922 \\
\hline Fulgencio Sancho & Vocal elect. & - & ALZ.V.1923 \\
\hline Manuel Marraco Ramón & Vocal elect. & - & ALZ.SCT.1922 \\
\hline Guillermo García Mercadal & Vocal elect. & - & - \\
\hline Román Izuzquiza & Vocal elect. & - & - \\
\hline Francisco Cano & Vocal elect. & - & - \\
\hline Marques de Arlanza & Vocal elect. & - & - \\
\hline Alejandro Palomar Mur & Vocal elect. & - & ALZ.VP.1922 \\
\hline Inocencio Jiménez Vicente & Vocal elect. & - & SCA.V.1922 \\
\hline - Antonio Lasierra Purroy & Vocal elect. & - & - \\
\hline José María Azara Vicente & Vocal elect. & - & SCA.P.1922 \\
\hline Mariano Gracián & Vocal elect. & - & - \\
\hline Tomas Lorente & Vocal elect. & - & SCA.V.1922/ALZ.CTD.1923 \\
\hline Francisco Bernad Partagas & Repres & Consejo Superior de Fomento & ALZ.P.1922. \\
\hline
\end{tabular}

Fuente: Boletín Oficial del Consejo Provincial de Fomento de Zaragoza. enero 1922. Memorias ALZ. Juntas Directivas SCA y CAZ. cursiva: mayores contribuyentes de Zaragoza y provincia..

Este monopolio de la representación consultiva, por parte de hacendados agrarios afines a las grandes organizaciones propietarias, se mantenía con ligeras modificaciones en 1915. El predominio de los hacendados católicos contrastaba entonces con la escasa presencia de los representantes de la ALZ, sin embargo existía una total continuidad respecto a los sectores socioeconómicos que ocupaban los cargos. Aunque no tenemos muchas referencias sobre los procesos electivos y las posibilidades de existencia de luchas, si que parece que ocasionaron a veces, tensiones entre las organizaciones. Esto demuestran algunas referencias en los libros de actas de la Casa de Ganaderos de Zaragoza, las dimisiones momentáneas de algunos dirigentes y la movilización en favor de candidatos 
propios. Por otro lado, y en relación con la elección de estos representantes entre las organizaciones, el proceso se llevaba a cabo en reuniones de sindicatos locales en las que la elección se hace por «aclamación» entre los miembros de la Junta Directiva ${ }^{90}$. Otras veces había una simple «reunión en la cumbre» de las mayores entidades, que solucionaba la disposición de los representantes en los sillones del Consejo, a través de los dirigentes de las distintas organizaciones ${ }^{91}$.

Las características económicas de los miembros del Consejo, tampoco habían cambiado demasiado en $1920^{92}$ o en 1922, tras el nuevo decreto. Como miembros de la Casa de Ganaderos se encontraban Manuel Pérez Cistué, diputado por las mismas fechas y Jorge Jordana Mompeón. José María Azara o Inocencio Jiménez, lo hacían en representación de los católicos y Fulgencio Sancho, Manuel Marraco y Alejandro Palomar, como dirigentes de la ALZ, a los que se unía Francisco Bernad Partagas como vocal en el Consejo Superior de Fomento. La composición de estas instituciones había mantenido así a lo largo de un periodo amplio del siglo $\mathrm{XX}$, una vinculación estrecha con los propietarios organizados, que en 1922 mostraba casi una representación simétrica entre todas las organizaciones zaragozanas, con una ligera inclinación de la balanza en favor de la ALZ.

Hasta aquí, queda reflejado el dominio propietario de los sectores organizados y su continuidad pero, ¿qué actividades desarrollaba la entidad por esas fechas?. A través de las memorias nos es posible recorrer cuales eran las intervenciones de estos propietarios y sus actividades en el Consejo. A pesar de que en 1915 el Comisario Regio señalaba como inconvenientes para la labor de la institución, «los escasos recursos» y la «falta de autoridad» de sus miembros, éste había participado en numerosos asuntos. En principio, como tal órgano consultivo, había enviado informes sobre los expedientes que se le presentaban, y que posteriormente eran remitidos a los centros con capacidad ejecutiva sobre aprovechamientos de aguas, reformas de ordenanzas de riegos y constitución de comunidades de regantes. Por otro lado, se habían informado numerosos

\footnotetext{
${ }^{0}$ Coincidiendo con los momentos bajos del SCA, la Caja de Aborros y Préstamos del Santísimo Cristo de Tarazona votaba en 1917 la candidatura de la ALZ. ACSAT. Libro de actas de la Caja de Aborros y Préstamos del Santísimo Cristo. Sesión 8-11-1917. "Se dio lectura de la comunicación y acta emitida por la Asociación de Labradores de Zaragoza, para que dieran su aprobación los señores que componen esta Junta y quedaron conformes con que los nombres que en ella se detallan ...que han de formar parte del Consejo Provincial de Agricultura, y por lo tanto diose por aprobada...» Durante los años veinte sin embargo, se producía una movilización a favor de los candidatos católicos en la comarca de Tarazona, ACSAT. Libro de actas de la Federación de Tarazona. Sesión 22-4-1928. En Los Fayos, APJR. Libro de actas del Sindicato Agrícola Católico de Los Fayos. Sesión 22-4-1928.

${ }^{91}$ ACGZ. Libro de actas. Junta General, 29-6-1908. / Libro de actas. Junta Directiva, 1-12-1908.

92 Los miembros del Consejo en 1920 también estaban relacionados con las grandes organizaciones agrarias. Así por ejemplo encontramos de nuevo a Manuel Marraco, Alejandro Palomar, Antonio Casaña o Manuel Pérez Cistué de la Casa de Ganaderos. EN, 16-3-1920. Consejo Provincial de Fomento.
}

Hispania, LXI/2, núm. 208 (2001) 619-660 
expedientes sobre subvenciones y demandas de ayuda económica para asociaciones agrícolas y comerciales ${ }^{93}$.

\section{Expedientes tramitados por el Consejo Provincial de Fomento de Zaragoza. 1911-1915.}

\begin{tabular}{l|c|c|}
\hline EXPEDIENTES INFORMADOS FAVORABLEMENTE & $\mathrm{N}^{\circ}$ & $\%$ \\
\hline Subvenciones a sindicatos agrícolas locales (1) & 3 & 4,23 \\
\hline Subvenciones a cámaras agrícolas locales (2) & 11 & 15,49 \\
\hline Subvenciones a grandes organizaciones agrarias (3) & 11 & 15,49 \\
\hline Subvenciones a la Cámara Comercio (4) & 3 & 4,23 \\
\hline Expedientes de constitución de comunidades regantes & 18 & 25,35 \\
\hline Expedientes de aprovechamiento de aguas & 9 & 12,68 \\
\hline Expedientes de proyectos de pantanos presas y riegos en general & 5 & 7,04 \\
\hline Subvención a ayuntamientos (concursos) & 2 & 2,82 \\
\hline Varios & 9 & 12,68 \\
\hline \multicolumn{1}{c|}{ Total } & 71 & 100,00 \\
\hline
\end{tabular}

(1) Sindicato Agrícola de Tauste, Tarazona y Bujaraloz. (2) 7 para la CAZ, 3 para la Cámara Agrícola de Calatayud y uno para la Cámara Agrícola de Tauste. (3) 5 para la ALZ, 5 para la FAA y una para la Unión Vitícola Aragonesa. (4) Todas para la Cámara de Comercio de Zaragoza.

Fuentes: CONSEJO PROVINCIAL DE FOMENTO DE ZARAGOZA, (1914) Memoria general de los trabajos realizados desde su constitución basta junio de 1914, Imp. Heraldo de Aragón, Zaragoza. pag. 7-16. CONSEJO PROVINCIAL DE FOMENTO DE ZARAGOZA, (1916) Memoria general de los trabajos realizados desde julio de 1914 basta 31 de julio de 1915, Zaragoza, Heraldo de Aragón. pag. 10-13.

Una vista de conjunto a esta labor entre, 1911 y 1915 , muestra por un lado la debilidad general de las ayudas concedidas y el carácter testimonial de aquellas otorgadas a los sindicatos agrícolas locales. La mayoría de estas se habían orientado hacia las cámaras agrícolas e incluso hacia las grandes organizaciones, que aunque con abundantes recursos propios, las solicitaban como base para la constitución de sus cajas de ahorros. Sin datos sobre la cuantía de las mismas no podemos establecer sin embargo conclusiones válidas, a no ser la de constatar su debilidad respecto al amplio número de entidades agrícolas de la provincia de Zaragoza, y su concentración en un número reducido y restringido de entidades, que bien disponían de recursos propios como la ALZ, — a destacar la curiosa ausencia del SCA en los expedientes-, o carecían de actividades

${ }^{33}$ EN, 23-2-1915. Subvenciones en el Consejo Provincial de Fomento. Todavía en 1926 y con motivo de las subvenciones concedidas en periodo de la Dictadura, se señalaba la necesidad de presentar estas solicitudes en el Consejo Provincial. EN, 17-10-1926. RO. 15-10-1925. Las subvenciones a las cámaras y sindicatos agrícolas. 
prácticas, más allá del mantenimiento de su supervivencia burocrática y de la organización de algún concurso agronómico, como era el caso de la Federación Agraria Aragonesa y de la Cámara Agrícola de Zaragoza. Entre la finalidad de las ayudas se señalaba la necesaria «financiación de la entidad» aunque en el caso de la Cámara Agrícola de Tauste se uniese la concesión a la adquisición de maquinaria agrícola. Cuando el Boletín del Consejo recogía las labores llevadas a cabo durante 1921, estas mostraban tan sólo la aprobación favorable de tres subvenciones, que se habían distribuido de nuevo entre la ALZ, el SCA y la Cámara Agrícola de Zaragoza ${ }^{94}$.

Dominaban entre las actividades las solicitudes sobre concesiones de aprovechamiento de aguas. Como ejemplo, el ayuntamiento de Ariza solicitaba una concesión para abastecer al vecindario, el Conde de Sobradiel lo hacía para aprovechar aguas del Ebro destinadas a sus fincas en esta localidad y en el mismo sentido se dirigía para solicitar otra concesión la Alcobolera Agrícola del Pilar, los industriales de las minas de Tierga, el propietario Francisco Delgado o la Sociedad Saltos del Huerva y del Jalón. En relación con las comunidades de regantes, la mayoría respondía a fundaciones de estas entidades sin embargo, también había modificaciones de estas con reclamaciones en ocasiones frente a sindicatos de riegos. Finalmente, se completaba la actividad informadora sobre las obras de riegos y construcción de pantanos y presas, convirtiendo a la institución en intermediaria con derecho a veto y a modificación, y con capacidad para retardar, retener o denegar incluso, los expedientes que se presentaban, y que tras su informe, iban destinados a la administración ejecutiva. Una labor, que pese a no sustituir la decisión final del Gobierno, significaba una nueva componente de poder que fue aprovechada por los propietarios organizados.

Las iniciativas y gestiones realizadas se habían dirigido también a elevar propuestas e iniciativas, estableciéndose incluso una importante comunicación con otras entidades provinciales similares, para apoyar demandas conjuntas Como ejemplo, en 1914 se ponían en comunicación con entidades castellanas con motivo de los Bonos de Importación de Trigos. Al año siguiente, las gestiones iban encaminadas a enviar otro informe al Consejo Superior, estableciendo las posiciones de los sectores cerealistas en relación con el arancel, o se dirigían a elevar al Consejo Superior los perjuicios ocasionados por los proyectos de zonas neutrales. En el mismo sentido, exigía la modificación de las disposiciones legales relacionadas con la venta de abonos o se recogían proposiciones sobre los intereses agrícolas y ganaderos en las roturaciones de montes. También intervino el Comisario Regio en las actividades destinadas al cobro de la remolacha en 1914, en clara unión con la ALZ95.

\footnotetext{
${ }_{94}$ Boletín Oficial de Consejo Provincial de Fomento de Zaragoza, enero 1922. Director: José Cruz Lapazarán. pag.3

95 BALZ, marzo 1914. Junta de Gobierno 5-2-1914.

Hispania, LXI/2, núm. 208 (2001) 619-660
} 
Para completar las actividades, se elevaba un informe sobre los problemas de comunicaciones en la provincia, a partir de un cuestionario realizado por el Consejo en los ayuntamientos sobre necesidades de infraestructuras, que los municipios se habían encargado de llenar de puentes, ferrocarriles, carreteras y caminos vecinales. Como parte integrante de los informes de 1911 y 19.13 se señalaba por ejemplo: "Se informó a la Jefatura de Obras Públicas de la provincia, acerca de las carreteras de la misma que ha de construir el Estado».

El cuadro de intervenciones se completaba reiterando el reconocimiento de las organizaciones propietarias en el seno de la administración. En este sentido, volvía también a dirigirse una demanda a la Dirección General de Agricultura, señalando que «era de oportunidad notoria la mayor intervención posible de la Asociación General de Ganaderos», en relación con los aprovechamiento forestales. Finalmente, se remitían estadísticas sobre agricultura y ganadería, y se publicaban hojas divulgadoras sobre las plagas del campo o estudios sobre múltiples temas agronómicos realizados por los técnicos de la administración provincial ${ }^{96}$. Una pluralidad de intervenciones, que necesitaría sin embargo para su análisis de aquellas que se rechazaron, pero que da una idea de la orientación que los propietarios organizados pretendían imprimir en la labor de estos centros, encaminándolos hacía la divulgación agronómica, hacia la organización del arancel y el comercio de abonos o hacia el incremento de su presencia cerca de la gestión administrativa. En definitiva, todos aquellos componentes, que configuraron el discurso de los propietarios en las encorsetadas asambleas agrarias.

Cuando en el marco de la Dictadura de Primo de Rivera (RD. 27-7-1929 Organización Agropecuaria), se producía un incremento de la impronta corporativa y un proceso de transformación de alguno de los centros administrativos consultivos, la presencia de los representantes de las organizaciones agrarias se iba a seguir manteniendo. La AAE continuaba demandando una mayor actividad de los denominados «servicios agrosociales», señalando incluso «el derecho a intervenir en la estructura del servicio técnico oficial» ${ }^{97}$. No obstante, la legislación mantuvo en principio la separación entre técnicos y centros consultivos, concediendo gran importancia a los órganos provinciales, en concreto a las Diputaciones, y creando dos entidades. Por un lado el Consejo Provincial de Economía, directo heredero de los consejos provinciales de Fomento, y junto a ellos a los nuevos Consejos Provinciales Agropecuarios.

${ }^{96}$ Las publicaciones agronómicas realizadas por el Consejo en Boletín Oficial del Consejo Provincial de Fomento de Zaragoza, enero 1922. pag. 7-8. Como ejemplo, CONSEJO PROVINCIAL DE FOMENTO DE ZARAGOZA (1913) Resumen de los trabajos llevados a cabo por la Sección Agronómica conducentes a la extinción de varias plagas del campo en el año 1913, Zaragoza, Tip. G. Casañal. CONSEJo Provincial DE FOMENTO DE ZARAGOZA. (1916) Conferencias de divulgación sobre enfermedades de las plantas cultivadas, Zaragoza, Imp. Hospicio Provincial. CONSEJo PRovinCIAL DE FOMENTO DE ZARAGOZA (1921) Memoria de los trabajos de extinción de la langosta practicados en la provincia de Zaragoza bajo la dirección del Servicio Agronómico, Zaragoza, Imprenta Hospicio Provincial.

97 BALZ, septiembre 1928. Comunicado Asociación de Agricultores de España.

Hispania, LXI/2, núm. 208 (2001) 619-660 
El Consejo Provincial de Economía, (RD 16-2-1927)98 estaba encargado de organizar las fuerzas económicas y mercantiles, con la finalidad de hacer propuestas y de asesorar en aquellos temas relacionados con sus respectivas áreas productivas, enlazando estos con el Poder Central. A su vez, tenían capacidad para recoger las peticiones de revisión arancelaria sobre las diferentes partidas, como institución colaboradora del Consejo de Economía Nacional. Estos centros estaban compuestos por representantes de entidades agrícolas, industriales y comerciales, a cuyo frente se encontraba el Comisario Regio de Economía Nacional, nombrado por el ministro. La Junta de la ALZ proponía de nuevo a Manuel Marraco como vocal de esta institución, continuando así la presencia de los dirigentes agrarios en estos centros ${ }^{99}$.

Junto a estas entidades, los efímeros Consejos Provinciales Agropecuarios, creados en 1929 con sede en las diputaciones provinciales, también pretendían convertirse en centro de reunión de los diputados, técnicos-funcionarios, y seis "vocales asesores» elegidos entre las asociaciones agrícolas, a razón de un voto cada 25 socios, sin que los labradores no asociados pudieran votar, y con presencia de arrendatarios y propietarios ${ }^{100}$. Al quedar en manos de las Diputaciones Provinciales algunos de los servicios agropecuarios que había venido realizando el Estado central, se colocaba al frente del servicio agrícola a un ingeniero agrónomo, el Consejo Provincial Agropecuario se convertía en centro «asesor». Los Consejos atenderían además a la organización de asociaciones agrícolas y a la información de propuestas gubernamentales. A pesar de estas atribuciones sin embargo, desde la ALZ se consideraba que «la propiedad territorial» requería una "organización oficial» como "cauce legal de sus intereses», sin que la representación en estos consejos provinciales se considerara suficiente. Unas críticas, que no impedían que en la elección de nuevo se generaran conversaciones entre los representantes de las principales organizaciones agrarias de la capital, para distribuir los cargos ${ }^{101}$.

La organización en 1929 de unas efímeras cámaras de la propiedad rústica (RD 6-9-1929), concebidas como órganos consultivos ${ }^{102}$, y constituídas en principio, como sustitución de las cámaras agrícolas provinciales, también originó un interés en las organizaciones agrarias. Debían pertenecer a estas todos los propietarios de la provincia que pagasen más de 25 pesetas de contribución

\footnotetext{
98 Esta entidades fueron modificadas en 1929, dándoles el mismo carácter de los Consejos Provinciales de Agricultura de 1859, (RD 29-12-1928). Posteriormente, en medio de continuos titubeos legales, pasarían a denominarse Juntas Provinciales de Economía . (RD. 6-3-1930).

99 BALZ, septiembre 1927. BALZ, noviembre 1927. Consejo Provincial de Economía.

100 BALZ, noviembre 1929. Consejos Agropecuarios Provinciales.

101 BALZ, enero 1930. Sesión ordinaria 7-12-1929. BALZ, febrero 1930. Junta de Gobierno. Sesión ordinaria 14-1-1930. BALZ, abril-mayo 1930. Junta de Gobierno 7-2-1930.

102 En 1930, el RD 13-2-1930 suprimía las cámaras de la propiedad rústica, reestableciendo las cámaras agrícolas provinciales y quedando éstas constituidas por las mismas personas, que las integraban antes del decreto de disolución.
}

Hispania, LXI/2, núm. 208 (2001) 619-660 
territorial, siendo organismos con carácter de corporaciones oficiales, dependientes del Ministerio de Economía Nacional. Tenía como objeto especial por ejemplo, la capacidad de proponer y solicitar al Poder Público resoluciones relacionadas con la propiedad rústica, representaba a la clase patronal agrícola en ayuntamientos, corporaciones y centros públicos, promoviendo las solicitudes, recursos y procedimientos convenientes a la propiedad rural, formaba estadísticas sobre la propiedad, o concertaba con el Estado, provincia, ayuntamiento y mancomunidades el cobro de contribución, arbitrios e impuestos relacionados con estos bienes.

Cada partido judicial elegía tres vocales, pudiendo votar todos aquellos que contribuían con más de 25 pesetas de contribución territorial, inscritos en el seno de la Corporación. Esta labor reconocida por ley, volvía a movilizar a los dirigentes agrarios de la ALZ y del SCA, que acabarían ocupando buena parte de los cargos. Aunque dentro de la ALZ se consideró siempre su instauración como innecesaria, al igual que lo eran las cámaras provinciales, su actitud respecto a estos centros fue la misma que frente a las antiguas cámaras agrícolas, la de ocupar todos los cargos existentes en estas, en previsión de su reconocimiento oficial. Las atribuciones que les concedía el decreto eran vistas por la propia ALZ como «un elemento formidable de caciquismo», sin embargo los poderes concedidos les hicieron tomar parte activa a favor de candidatos agrarios propios ${ }^{103}$.

\section{Dirigentes agrarios candidatos a la Cámara de la Propiedad Rústica de Zaragoza 1929.}

\begin{tabular}{|c|c|}
\hline Partido Judicial & Asociación de Labradores Zaragoza/ Casa de Ganad \\
\hline Caspe & Juan Fabiani Díaz De Cabria \\
Daroca & Rafael Ricarte Lafuente \\
Daroca & José María Vargas Lavigne \\
Pina de Ebro & Joaquin Aranguren Genzor \\
Pina de Ebro & Tomas Quintin Mancholas \\
Sos del Rey Católico & Agustín Gros Ruata \\
Tarazona & Francisco Bernad Partagas \\
Zaragoza (Dist. Pilar) & Jorge Jordana Mompeón \\
Zaragoza (Dist. San Pablo) & Alejandro Palomar Mur \\
\hline Partido Judicial & Sindicato Central de Aragón/ Unión de Remolacheros \\
\hline Ateca & Fernando Hueso Rotland \\
Belchite & Mariano Sancho Rivera \\
Ejea de los Caballeros & Ignacio Monserrat de Pano \\
\hline
\end{tabular}

103 BALZ, septiembre 1929. Las Cámaras de la Propiedad Rústica. 


\author{
Ejea de los Caballeros \\ Pina de Ebro \\ Sos del Rey Católico \\ Zaragoza (Dist. Pilar) \\ Zaragoza (Dist. Pilar) \\ Mariano de Ena Valenzuela \\ Manuel Ardid de Acha \\ Joaquin López Monguilan \\ Antonio Casaña Pérez \\ Alejandro Palomar de La Torre
}

cursiva: mayores contribuyentes de Zaragoza y provincia.

*Sólo se recoge la filiación relacionada con el SCA, ALZ, CGZ y Unión de remolacheros. No disponemos de datos sobre las otras entidades que formaban la candidatura.

AMBE. Comunicado de las entidades agrarias con motivo de la elección de la Cámara de la Propiedad Rústica y candidatura propuesta. $(125-1)$

Las reuniones entre los representantes de las diferentes entidades llevó a una candidatura conjunta de las organizaciones agrarias zaragozanas, con representaciones proporcionales que en el marco de la Dictadura acabó por copar todos los cargos. Como se señalaba desde la Junta Directiva de la ALZ, se trataba «de conseguir acuerdo entre todas ellas, al objeto de que el nuevo organismo resulte investido del máximo prestigio e indiscutible autoridad.», lo que en la práctica significaba asegurar su presencia en cualquiera de las iniciativas institucionales, que reconocían su capacidad de representación de la agricultura en general ${ }^{104}$. La candidatura era finalmente propuesta por la Casa de Ganaderos de Zaragoza, la ALZ, el SCA, la Unión de Remolacheros, la Unión de Hortelanos y la Unión de Viticultores ${ }^{105}$.

Estos candidatos, que se autodefinían como de «máxima solvencia», «especializados agrónomos» y «entusiastas de las labores corporativas», eran en su mayoría a dirigentes de las principales organizaciones propietarias. En muchos de los casos, existía una continuidad en su presencia en órganos consultivos de la administración desde 1914. La propia endogamia y permanencia en el seno de entidades como la ALZ y la consolidación del SCA tras el periodo de la Primera Guerra Mundial, favoreció la existencia de una élite agraria movilizada, y que poseía un alto agrado de organización y un elevado interés a la hora de hacerse con estos cargos. Sus entidades eran además reconocidas como representantes privilegiados de la "Agricultura» en estos centros, lo que contribuyó a que se erigieran en «intérpretes» e «intermediarios» en el seno de la administración, utilizando sus redes establecidas por toda la provincia. Un elemento, que formó parte en cierta medida del engranaje, que hizo de estas organizaciones mecanismos de reproducción para los sectores propietarios que las dirigían, acrecentando su poder frente a otros miembros de la sociedad agraria y frente a este mismo

104 BALZ, noviembre 1929. Sesión Ordinaria 22-12-1929. BALZ, diciembre 1929. Junta de Gobierno. Sesión ordinaria 11-11-1929.

10s AMBE. Comunicado de las entidades agrarias con motivo de la elección de la Cámara de la Propiedad Rústica y candidatura propuesta. (125-1)

Hispania, LXI/2, núm. 208 (2001) 619-660 
grupo de élites, que poseyendo los mismos resortes patrimoniales carecían de redes de mediación institucional ${ }^{106}$.

\section{A MOdO DE BALANCE}

Por encima de la experiencia asociativa pegada a la realidad local y al lado de la empresa cooperativa comercial se fue edificando a comienzos del siglo XX un entramado de representaciones y mediaciones de intereses agrarios, dirigido por gerentes de las grandes organizaciones. Este proceso fue acompañado por un reconocimiento oficial desde el Estado al convertirlas en intérpretes de las demandas procedentes de unos sectores campesinos heterogéneos y crecientemente involucrados en el mercado. De este modo, se iba a poner de manifiesto a lo largo de este periodo el interés mostrado por ocupar cargos administrativos de carácter consultivo y por establecer conexiones con aquellos de carácter técnico como los Servicios Ágronómicos. Esta capacidad estuvo relacionada con el propio poder y con las relaciones políticas de la entidad en cuestión. De esta manera, la ALZ y el SCA se erigieron en representantes de Aragón frente a entidades menos pujantes de Teruel o Huesca.

La presencia en instituciones como el Consejo Superior de Fomento, la Junta de Aranceles y Valoraciones u otras menos estables como la Junta Consultiva del Crédito Agrícola o el Consejo del Banco de España se convertía en objetivo de los dirigentes de organizaciones agrarias de signo propietario. Esto llegaba a generar en algunos casos una oposición por parte de los sectores técnicos de la administración, cuando se definía el papel y el número de los entramados burocráticos agrarios en la gestión del Estado y a la hora de establecer competencias entre «técnicos» y «grupos de interés».

Estas actividades de los propietarios para formar parte de las instituciones llevaron en primer lugar a la movilización de Cámaras y organizaciones y a la búsqueda del voto. Con unas candidaturas ocupadas por elites y manteniendo al margen de este proceso a la mayoría de la población agraria se crearon sistemas electivos, que no contribuyeron a crear vías democráticas, sino que reproducían en su forma y fondo las características esenciales de la representación política clientelar de la Restauración.

Aunque las vías informales, que discurrían por la mediación de diputados regionales, se utilizaban para sustentar demandas y mediaciones relacionadas con la política agraria — aranceles, industria azucarera, abastos...- también se fue configurando este entramado formal, mediante el que los diferentes intereses económicos disponían de espacios de representación en el seno de la administración del Estado. Este estatus público progresivamente elaborado confor-

106 Ver CUISENIER, J.: (1966) «Functions économiques des organisations et des administrations agricoles en France» en Etudes Rurales, pag. 5-71.

Hispania, LXI/2, núm. 208 (2001) 619-660 
me se asentaban esas organizaciones conllevó un verdadero proceso de «privatización» de intereses en manos las grandes asociaciones agrarias. Esta participación significaba una nueva componente de poder para esta burguesía organizada, que además hacía en un principio de sus instituciones patronales y de sí mismos como «clase generale», los únicos mediadores de los intereses agrarios.

También los centros periféricos relacionados con el Ministerio de Fomento se convirtieron en centro de reunión de los propietarios organizados. Constituidos como órganos consultivos provinciales del Ministerio de Fomento en donde se mezclaban altos cargos de la administración con representantes de los intereses económicos locales, los dirigentes de la ALZ, el SCA y la Casa de Ganaderos se convirtieron en los mediadores de intereses agrarios. Con una presencia continuada a lo largo del siglo, los sectores técnicos de la administración comenzaban a formar parte de las redes relacionales de la burguesía agraria, siendo los encargados de emitir informes sobre temas relacionados con la agricultu$\mathrm{ra}$, las infraestructuras o la información de subvenciones a sindicatos y cámaras agrícolas. Los sistemas electivos establecidos con las organizaciones volvían a mostrar a escala local la movilización en favor de candidatos propios y los procedimientos escasamente democráticos con elecciones por «aclamación» o con «reunión en la cumbre de la Directiva».

Esta presencia, junto a su participación en comisiones y en la elaboración de proyectos formó parte en cierta medida del engranaje, que hizo de estas organizaciones mecanismos de reproducción para los sectores propietarios que las dirigían, acrecentando su poder frente a otros miembros de este mismo grupo de elites agrarias, que poseyendo los mismos resortes patrimoniales carecían de redes con lo que significativamente se denominaba «vida de relación» y «representaciones corporativas cerca del Estado». En conjunto, esta capacidad para intervenir en centros consultivos nacionales y provinciales incrementaba a lo largo del siglo el amplio radio de esfera de acción de los dirigentes agrarios en múltiples instituciones en las que se gestionaban recursos, se dirimían intereses, o se representaba al campesinado. 